\title{
Moderating Factors of Immediate, Gross, and Net Cross-Brand Effects of Price Promotions
}

\author{
Csilla Horváth \\ Institute for Management Research, Radboud University, 6500 HK Nijmegen, The Netherlands, \\ c.horvath@fm.ru.nl \\ Dennis Fok \\ Econometric Institute, Erasmus University Rotterdam, 3000 DR Rotterdam, The Netherlands,
} dfok@ese.eur.nl

\begin{abstract}
$\mathrm{T}^{\mathrm{h}}$ his article examines cross-price promotional effects in a dynamic context. Among other things, we investigate whether previously established findings hold when consumer and competitive dynamics are taken into account. Five main influential effects (asymmetric price effect, neighborhood price effect, asymmetric share effect, neighborhood share effect, and private label versus national brand asymmetry) appear jointly in the second layer of a pooled HB-VEC-VARX model, together with brand- and category-specific variables. This study tests the relative importance of these key factors across three scenarios: with no market dynamics, when only consumer dynamics are considered, and when competitive reactions are also taken into account. The results confirm all five influential effects, even if they are jointly estimated, and consumer and competitive dynamics are taken into account. National brand/private label asymmetry has the strongest influence on the cross-price promotional effects and becomes significantly stronger when consumer and competitive dynamics are taken into account. Dynamic consumer responses and competitive reactions both affect cross-brand price elasticities, and contrary to expectations, competitive reactions accumulate rather than diminish cross-price elasticities. Preemptive switching does occur; i.e., a brand's promotion in period $t$ hurts a competitor's sales in subsequent periods. Our findings are based on an extensive data set. To attain generalizable results, we analyze 33 categories in five stores-that is, 165 store/category combinations.
\end{abstract}

Key words: cross-price elasticity; price promotions; asymmetry; dynamic effects; competitive reactions; hierarchical Bayes

History: Received: July 21, 2008; accepted: August 16, 2012; Eric Bradlow and then Preyas Desai served as the editor-in-chief and Scott Neslin served as associate editor for this article. Published online in Articles in Advance November 30, 2012.

\section{Introduction}

Previous research has made substantial progress in quantifying the cross-brand effects of (promotional) price changes and in identifying the factors that moderate these effects (e.g., Allenby and Rossi 1991, Blattberg and Wisniewski 1989, Bronnenberg and Wathieu 1996, Sethuraman et al. 1999). Among the moderators, there are five relevant asymmetric and neighborhood effects: asymmetric price effect, neighborhood price effect, asymmetric share effect, neighborhood share effect, and private label versus national brand asymmetry.

According to the literature, immediate cross-brand price effects are asymmetric; that is, the impact of brand A's price change on brand $\mathrm{B}^{\prime} \mathrm{s}$ sales is not the same as the impact of $\mathrm{B}^{\prime}$ s price change on $\mathrm{A}^{\prime} \mathrm{s}$ sales. Research also shows that high-tier brands have a stronger effect than low-tier brands (e.g., Allenby and Rossi 1991, Blattberg and Wisniewski 1989, Bronnenberg and Wathieu 1996, Hardie et al. 1993,
Sivakumar and Raj 1997), that brands whose prices are similar have greater cross-price effects than brands that are priced farther apart (e.g., Kamakura and Russell 1989, Russel 1992, Sethuraman 1995, Sethuraman et al. 1999), and that larger brands have a stronger influence on competing brands' sales than smaller brands (Sethuraman and Srinivasan 2002, Sethuraman et al. 1999). These phenomena are referred to as asymmetric price effect, neighborhood price effect, and asymmetric share effect, respectively. Furthermore, according to the neighborhood share effect, brands with similar sizes are expected to experience larger cross-price effects than brands with more dissimilar sizes. Finally, according to the private label versus national brand asymmetry, national brands have been found to influence private labels more than the other way around (e.g., Aggarwal and Cha 1998, Blattberg and Neslin 1989, Sivakumar and Raj 1997).

Previous research has studied these effects in great detail but misses two important aspects. First, it 
focuses primarily on immediate cross-brand effects (Sivakumar 2000) of price changes and thus ignores the notion that competing brands operate in a dynamic environment. Second, although the different asymmetric and neighborhood effects are connected to each other, most extant research analyzes only a subset of them. This article fills these gaps in the literature by incorporating marketing dynamics and a broad set of variables into the analysis. We will first separately discuss the literature on dynamics and on moderators of cross effects. Next, we will further substantiate our contribution.

Two major dynamic processes have been identified that may influence the cross-brand effects of price changes: consumer dynamics and competitive dynamics. Consumer dynamics refers to consumers' delayed responses to changes in price and in other marketing variables. Such delay may arise, for example, from the "additional inventory of the promoted brand [that] preempts the consumers' purchase of a competing brand in the future" (Ailawadi et al. 2007, p. 450), resulting in a post-promotion dip for other brands in the category (Van Heerde et al. 2003). Competitive dynamics represents the reactions of competitors to a price change or another marketing activity of a brand. In today's intensely competitive marketing environments, price promotions can easily be matched by competitors, which may erase initial sales and profit gains from promotions (Balachander et al. 2010). The execution of most competitive reactions takes time, however. Therefore, the influence of competitive reactions emerges one or more periods after the promotion.

Several authors warn against possible inaccurate conclusions as a result of ignoring these dynamic processes, and they emphasize that dynamics should be taken into account to arrive at proper results. Fok et al. (2006), Kopalle et al. (1999), and Pauwels (2007) all stress the potential for erroneous conclusions that stem from disregarding the presence of consumer dynamics. Leeflang and Wittink (1996, 2001) argue that ignoring (dynamic) competitive reactions may lead to biased estimates of market responses to price and other marketing variables. These findings indicate that, rather than focusing only on immediate effects, a more realistic approach is to account also for dynamic consequences and concentrate on the socalled cumulative effects (i.e., the sum of immediate and all subsequent dynamic effects) of price changes (see, e.g., Dekimpe et al. 1999, Fok et al. 2006, Horváth et al. 2005, Pauwels et al. 2002) when analyzing crossprice effects.

Concerning the moderators of cross effects, even though the different asymmetric and neighborhood effects are related, extant research has analyzed only a subset of them in each analysis.
Sethuraman et al. $(1999$, p. 38) state that the observed cross-price asymmetry in the literature "may simply be due to the...correlation between price and market share across brands." In addition, Sethuraman and Srinivasan (2002) find that when controlling for asymmetric and neighborhood price effects simultaneously, the coefficient of the price asymmetry dummy becomes insignificant. Furthermore, privatelabel brands are typically less expensive (Hansen et al. 2006, Sivakumar and Raj 1997) and often smaller than national brands. Therefore, the usually observed inferior cross-price elasticities of these brands may arise (at least partly) from their inherently lower price and size. Consequently, to ultimately understand what shapes cross-price effects, all related variables should be included in one model.

This article broadens the analysis of (moderators of) cross-brand effects by including consumer and competitive dynamics and by relating the cross-price elasticities to all five relevant asymmetric and neighborhood effects at the same time. In our analysis, we focus on the effect of price promotions-that is, on the cross-brand price promotional elasticities-while controlling for changes in regular prices. Literature has shown that regular price changes and price promotions have different effects on sales (e.g., Bijmolt et al. 2005, Bucklin and Gupta 1999, Fok et al. 2006, Srinivasan et al. 2000). To account for this difference, we decompose actual prices into the regular price and a price promotion index. We focus on the impact of price promotions but include the regular price as a control variable.

To gain insights into the influence of consumer and competitive dynamics separately, we develop a hierarchical Bayes vector error correction (VEC) model and vector autoregressive model with explanatory variables (VARX) (hereafter, a HB-VEC-VARX model), which distinguish among immediate, dynamic consumer, and dynamic competitive cross-price effects. In other words, we compare cross-price elasticities across three scenarios: (1) considering only immediate (short-run) effects (immediate effects), (2) considering also dynamic consumer responses (gross effects), and (3) additionally considering dynamic competitive responses (net effects). We base our analysis regarding the second and the third points on the cumulative effects (the sum of immediate and subsequent dynamic effects), which is common practice in the dynamic sales response literature (see, e.g., Dekimpe et al. 1999, Fok et al. 2006, Horváth et al. 2005, Pauwels et al. 2002). Comparisons across the scenarios reveal how consumer dynamics (i.e., preemptive brand switching) and competitive reactions shape cross-price effects.

To understand how asymmetric and neighborhood effects influence cross-price promotional elasticities in 
such a dynamic context, we relate the cross-price elasticities to all relevant asymmetric and neighborhood effects in the second level of our model. These contain asymmetric price and share effects, neighborhood price and share effects, and national brand/private label asymmetries. We also control for the influence of brand- and category-specific variables.

In summary, we contribute to the literature in two major ways. First, we explore the impact of consumer and competitive dynamics on cross-price promotional elasticities. Second, we analyze the relative influences of a broad set of variables. We address the following important questions: Does preemptive switching as a result of price promotions occur, and does this result in cross-brand post-promotional dips? Are the findings on asymmetric and neighborhood effects robust to a more realistic dynamic setting? How do consumer and competitive dynamics alter the relative influence of asymmetric and neighborhood effects? Do the asymmetric and neighborhood effects prevail when simultaneously considered in one model, or does one effect dominate?

To the best of our knowledge, we are the first to investigate cross-price elasticities in both a comprehensive and dynamic framework. We substantiate this claim in Table 1, in which we summarize the literature on cross-price effects.

Analyzing cross-price effects in a realistic, dynamic context is essential for both researchers and managers. Doing so can offer new insights for researchers who use cross-price elasticities to examine competition, pricing, and substitution patterns. Furthermore, managers can use cross-price elasticities to formulate important tactical and strategic decisions about price and market segmentation and to gain insight into market structures. Conversely, managers who focus only on short-term cross-price elasticities and ignore the dynamic environment may make inadequate decisions that could seriously hamper the company in the future.
Our main findings are that (1) preemptive switching does occur, i.e., a brand's promotion in period $t$ hurts a competitor's sales in subsequent periods; (2) national brand/private label asymmetry is the most dominant form of asymmetry; (3) competitive reactions accumulate rather than diminish cross-price elasticities; and (4) the results on the asymmetric and neighborhood effects hold even if they are jointly included in a model and even when we integrate consumer and competitive dynamics. Our findings are based on an extensive data set. To attain generalizable results, we analyze 33 categories in five stores (i.e., 165 store/category combinations).

The remainder of the paper proceeds as follows. In $\$ 2$, we outline our conceptual research framework and derive hypotheses from extant literature. We specify the models in $\S 3$, and we present the data and results in $\S 4$. We conclude with a discussion in $\S 5$.

\section{Conceptual Model and Literature Review}

We depict the conceptual framework that guides our research in Figure 1. We call the brand whose sales are affected by the price promotion of another brand the victim brand in our framework and the promoted brand the attacker brand. We focus on the immediate, gross, and net effects of price promotions of brand A (attacker) on the sales of a rival brand V (victim), in relation to variables that describe the relative positioning of the two involved brands, brand variables, and category variables. In addition, because the two brands' cross-price promotional elasticities may be dependent not only on their relative price and size positioning but also on their absolute size and price level, we use average price and size levels of the two brands as control variables.

For each variable, we summarize the relevant literature and, if possible, provide a hypothesis for the expected moderating effect. In many cases, especially for the complex net effect, we cannot formulate such

Table 1 Articles on Factors That Explain Heterogeneity in Cross-Price Elasticities

\begin{tabular}{llcc}
\hline Factor & \multicolumn{1}{c}{ Related article(s) } & $\begin{array}{c}\text { Dynamic consumer } \\
\text { responses considered? }\end{array}$ & $\begin{array}{c}\text { Competitive reactions } \\
\text { explicitly considered? }\end{array}$ \\
\hline Asymmetric price (quality) effect & $\begin{array}{c}\text { Allenby and Rossi (1991), Allenby et al. (2010), Agarwal (2002), } \\
\text { Blattberg and Wisniewski (1989), Bronnenberg and Wathieu (1996), }\end{array}$ & No & No \\
& Kamakura and Russell (1989), Sethuraman et al. (1999), Sivakumar \\
and Raj (1997), Sivakumar (2004), Wedel and Zhang (2004) & No & No \\
Neighborhood effect & Sethuraman et al. (1999), Sivakumar (2000, 2003) & No & No \\
Asymmetric size effect & Chintagunta (1993), Kamakura and Russell (1989), Sethuraman (1995), & No \\
National brand vs. private label & Sethuraman and Srinivasan (2002) & Aggarwal and Cha (1998), Agarwal (2002), Raju et al. (1995), Sayman & No \\
Number of brands in category & et al. (2002), Sethuraman (1995), Sethuraman et al. (1999), & No & No \\
Food/nonfood categories & Sethuraman and Srinivasan (2002), Sivakumar (2007) & No \\
\hline
\end{tabular}




\section{Figure 1 Conceptual Research Framework}

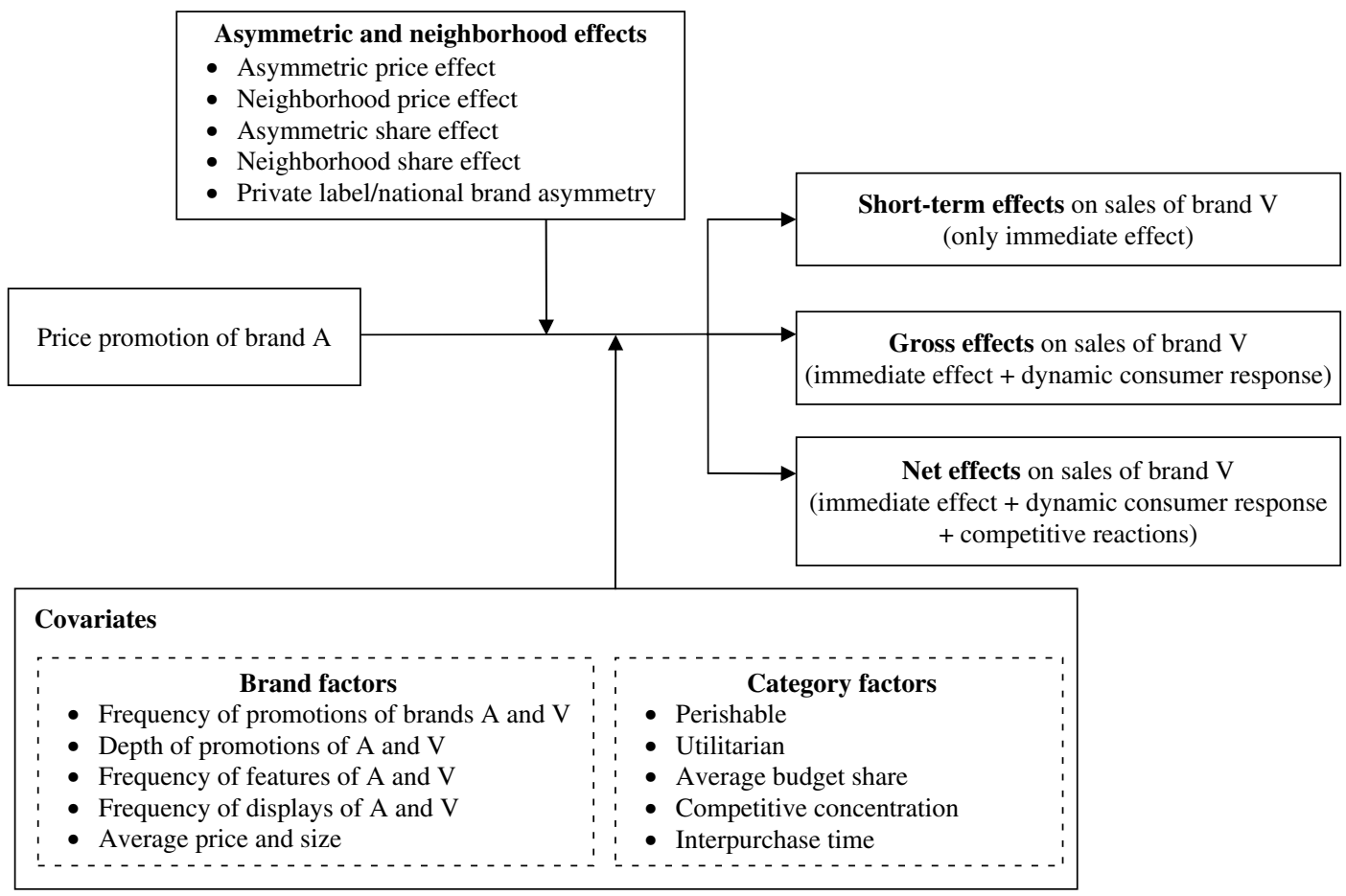

Note. A refers to the attacker and $\mathrm{V}$ to the victim brand.

hypotheses from existing literature, so our investigations in these cases represent a search for empirical evidence on the relationship between the considered characteristics and the (dynamic) effects of price. For each moderating variable, we first discuss its influence on the immediate cross-price elasticities. Then, we review the literature on consumer dynamics, and finally, on competitive reactions. Last, we summarize the derived hypotheses for moderation of the immediate, gross, and net effects.

\subsection{Asymmetric and Neighborhood Effects}

Asymmetric price effect: The asymmetric price effect states that "a price promotion by a higher-priced brand affects the share of a lower-priced brand more so than the reverse" (Sethuraman et al. 1999, p. 23). Several phenomena contribute to the asymmetric price effect. First, higher-priced brands are believed to offer better quality. Price promotions make these brands affordable to price-conscious consumers who usually buy cheaper brands that are also of lower quality, and thus these customers are highly inclined to substitute for their standard purchase. A less expensive brand on promotion offers lower gained value, so consumers should be less likely to switch to them (Allenby and Rossi 1991, Blattberg and Wisniewski 1989, Sethuraman et al. 1999). Second, asymmetry can arise from differences in the customer base, such that high-quality (high-priced) brands usually have more loyal customers than low-quality (inexpensive) brands. This distinction contributes further to the greater substitution effect for the better-quality brand.

Neighborhood price effect: According to the neighborhood price effect hypothesis, brands with prices closer to one another experience larger cross-price effects than brands with more dissimilar prices. Kamakura and Russell (1989) show specifically that consumers tend to switch only among brands within a certain price range. Rao (1991), Russel (1992), Sethuraman (1995), and Sethuraman et al. (1999) also find additional empirical evidence on the neighborhood effect.

Consumers are more inclined to accelerate their purchase and stockpile the discounted brand if it is better than (asymmetric price effect) or more similar to (neighborhood price effect) their regular brand purchase. In addition, managers often restrict their attention to a subset of competitors (DeChernatony and Johnson 1993, Leeflang and Wittink 1996) and focus mainly on the competitors with similar positioning and similar price levels that are likely to serve a similar consumer base.

Overall, if the attacker is priced higher than the victim brand or if the two brands' prices are similar, the immediate cross-price effect should be greater. We also expect asymmetric and neighborhood price effects to gain strength when we consider dynamic consumer responses. Finally, in these cases we also 
expect more intense competitive reactions from the victim brand, so the aggregate outcome of the two effects on the net cross-price elasticities depends on the relative magnitude of consumer responses and competitive reactions.

Asymmetric share effect: Because of their popularity, high awareness, and brand salience, larger brands have greater drawing power in general (Hauser and Wernerfelt 1989, Kamakura and Russell 1989, Rao and Miller 1975), and smaller brands tend to attract less loyalty from their buyers (Ehrenberg et al. 1990, Martin 1973). This asymmetric share effect phenomenon (Kamakura and Russell 1989, Pauwels 2007, Sethuraman 1995) implies that large brands' promotions hurt smaller brands while being less vulnerable to smaller brands' discounts. Because these larger brands usually also offer higher quality, stockpiling is more beneficial for customers, so competitors may suffer a further decrease in sales in future periods. Larger attacker brands also operate through broader distribution channels and have larger and more noticeable shelf space (Reibstein and Farris 1995, Steenkamp et al. 2005). Therefore, they are more visible not only to customers but also to competitors (Gatignon et al. 1997). Furthermore, if the market activities of powerful brands are perceived as threatening, the smaller, more flexible brands might respond quickly and easily. In addition, Dolan and Jeuland (1981) find that large firms tend to avoid price competition. Thus, price changes by larger brands likely induce stronger reactions among competitors (Dutton and Jackson 1987, Gatignon et al. 1997). Steenkamp et al. (2005, p. 46) offer empirical confirmation that "the more powerful the attacker, the greater the price promotion reaction elasticity." On the whole, a larger attacker and a smaller victim brand should face an increased immediate cross-price effect. Furthermore, we expect these effects to be even stronger for the gross cross-price effect. We also anticipate stronger competitive reactions, which prevents us from formulating the expected moderation for the net effect.

Neighborhood share effect: Analogous to the neighborhood price effect, we include a variable that captures the neighborhood share effect. By doing so, we explore whether brands with similar sizes experience larger cross-price effects than brands with more dissimilar sizes. This phenomenon is called the neighborhood share effect. Larger brands, with a broader customer base, brand equity, and brand salience, probably attract brand-conscious customers, whereas smaller brands attract less brand-conscious but more price-conscious people. Brand-conscious customers are more likely to switch to another highequity brand, whereas price-conscious customers may switch to similar cheap brands and may even stockpile when they are on sale. The customer base of brands with similar sizes is usually also similar. Therefore, brand managers likely consider brands of similar sizes more threatening than brands of different size and therefore are more inclined to react. Thus, we expect greater immediate cross-price promotional elasticity, an even greater gross effect, and an intensified competition between brands with similar sizes.

National brand/private label asymmetry: According to the national brand/private label asymmetry hypothesis, national brands steal significant shares from private labels when they reduce their prices, whereas promotion-based share gains for private labels are rather insignificant (Aggarwal and Cha 1998, Blattberg and Neslin 1989). This is largely due to the more price-sensitive (Aggarwal and Cha 1998, Ailawadi et al. 2001), less brand-conscious (Ailawadi et al. 2008), and less loyal (Sethuraman et al. 1999) customer base of private labels. In general, private labels are cheaper than national brands, which has several implications for their performance. First, because low price may be attributed to some problematic aspect of a product, private labels may be perceived as inferior (Garretson et al. 2002) and of lower quality (Sivakumar and Raj 1997). Second, research has shown that heavy private label users have lower income (Dhar and Hoch 1997). This suggests that the main motivation of customers for purchasing private labels is their lower price. In line with this, according to Bartha and Sinha (2000) and Rothe and Lamont (1973), price consciousness is a predictor of private label usage. Finally, private labels can usually spend less money on advertising, and thus they have lower brand equity (Sivakumar and Raj 1997) than national brands.

Because of the differences between national brands and private labels, price promotions of national brands offer better switching incentives (both immediate and preemptive switching) than those of private labels. Private label customers also tend to be less loyal and thus more inclined to switch away if a national brand is for sale than the other way around. The perceived quality advantage should be particularly high when the attacker is a national brand and the victim is a private label, moderate if both brands are national brands, and low if the attacker is a private label and the victim is a national brand. The immediate and gross effects should similarly decrease if the quality advantage decreases. Competitive moves by national brands with broad market channels likely seem more threatening to a private label than the other way around. Moreover, national brands are less likely to retaliate against private labels, because they "have much to gain from the collaborative relation with retailers" (Steenkamp et al. 2005, p. 38), and 
their ability to react is restricted (Steenkamp et al. 2005). Yet, because the retailer exerts significant control over marketing activities, it may also feel less threatened by national brand promotions. The retailer has an incentive to maximize store performance, not just private label sales. Therefore, we recognize that private labels might not initiate strong competitive responses to national brand promotions. Considering these opposing forces, we remain uncertain about the overall effect of competitive dynamics.

\subsection{Other Covariates}

2.2.1. Brand-Specific Characteristics. At the brand level, we distinguish between the activities of the attacker and the victim brands; thus, we develop hypotheses for both.

Frequency of price promotions: Frequent price promotions erode brand equity and may convey a low-quality brand image (Yoo et al. 2000). Thus, price discounts by a frequent promoter should be less attractive than discounts by similar brands that undertake infrequent promotions and thereby stimulate less brand switching and less stockpiling behavior. Similarly, frequent discounts by the victim brand can lower its perceived quality, and so its market share should respond more to competitors' price discounts (see also Fok et al. 2006). The frequently promoted brands then draw a larger proportion of price-sensitive customers (Zenor et al. 1998), who are likely to switch when competitive brands are on sale. Because the frequent promotions also make brands more noticeable to competitors, they increase the likelihood of reaction. The magnitude of marketing activities in a retail store could also reflect the power and importance of the brand for the retailer. Overall, we expect the frequency of price promotions by the attacker brand to reduce and that by the victim brand to increase the immediate cross-brand price elasticity. We also expect these influences to hold for the gross and net effects.

Average depth of promotions: Consumers often suspect that deep discounts indicate low quality (Jedidi et al. 1999, Mela et al. 1998) or unjustly high margins. If the perceived quality of the attacker is low, cross-price elasticities should be small. A low perceived quality of the victim should have the opposite effect. Furthermore, deep price promotions by the attacker brand offer a high financial incentive to buy additional items and stockpile, which can result in a prolonged sales dip for the victim brand. Our expectations for the competitive responses are similar to those for the frequency of promotions. Therefore, in general, deep discounts by the attacker should decrease the immediate effect, and those of the victim brand should increase this effect. These expectations should also apply to the net and gross effects.
Frequency of feature and display activities: Features and displays often help increase or maintain brand awareness. The frequency of such feature and display activities should increase the likelihood of a brand appearing in consumers' consideration set (Keller 1993), which enables consumers to notice its price promotions. However, frequent marketing activity also draws competitors' attention and stimulates them to react. The frequency of marketing activities also reflects the power and importance of the brand for the retailer. In summary, price promotions by an attacker brand that engages in frequent display or feature activities should have high immediate and gross cross-price promotional elasticities, but the more intense competitive reaction may erode some effects, leaving the moderating influence on the net effect unclear. We cannot formulate similar hypotheses for the immediate and gross effects of frequent features and displays by the victim brand. However, we expect that a victim brand with more frequent display or feature activities reacts more intensively.

Average price and size: Previous research suggests that "successful brands with a large customer franchise are ... likely to have adopted marketing strategies aimed at retaining their customers" (Raj 1985, p. 54) and that the perceived higher quality of larger and higher-priced brands leads to more loyalty and, thus, less brand switching. Greater loyalty also prevents customers from stockpiling a competing brand when it is on sale. In line with these arguments, we expect the brands with higher prices and sizes to have lower immediate and gross cross effects, though formulating similar hypotheses for the net effect is difficult.

\subsubsection{Category-Specific Characteristics.}

Perishability: The perishable nature of a product category is an important feature with regard to the ownprice effects (Fok et al. 2006, Narasimhan et al. 1996, Raju 1992). In a category with nonperishable products, a large part of the own-price effect may arise from brand switchers with a high propensity to stockpile. This leads to more preemptive brand switching (Ailawadi et al. 2007). In addition, in less perishable categories, the victim brand has a greater incentive to retaliate quickly to price promotions (Steenkamp et al. 2005). Therefore, we expect stronger immediate and gross effects in less perishable categories. Again, the competitive reaction may counterbalance the gross effect.

Utilitarian nature: Shoppers with relatively low incomes constitute a relatively large proportion of the consumer population for necessity goods (Bell et al. 1999, Wakefield and Inman 2003). This group is more price sensitive and prone to deals. Furthermore, in low-involvement categories, brand awareness may be a sufficient condition for brand choice 
(Keller 1993). Accordingly, we predict more brand switching and larger cross-brand price effects in more utilitarian categories. Moreover, impulse purchases generally involve hedonic categories. Steenkamp et al. (2005) find that victim brands are more prone to react aggressively to promotions in categories open to impulse purchases, so the lower expected competitive reaction in utilitarian categories may increase the cross-price effect.

Average budget share: The average budget share of a category measures the category's financial importance to the consumer. Consumers tend to react strongly to promotions in categories that take up a large part of the budget (Fok et al. 2006, Macé and Neslin 2004). Therefore, we expect the immediate cross-price effect to be large in such categories. We also expect consumers to stockpile the product to take maximum advantage of the discount. Finally, we expect competitors to react strongly to promotions in a high-budget category because of the high financial stakes. In turn, this leads to a high immediate effect and a high gross effect in a large-budget category. It is not possible to offer a hypothesis for the net effect.

Competitive concentration: In the presence of several similar brands, which implies low competitive concentration, brand switching is a dominant source of variability in brand sales (Narasimhan et al. 1996, Raju 1992). Conversely, many competitors can also imply more differentiation, such that brands are less exposed to competitors' actions or brand switching (Ailawadi et al. 2007, Macé and Neslin 2004). Sethuraman et al. (1999) also conclude that cross-price effects are stronger when there are fewer competing brands in the product category. Regarding competitive reactions, Steenkamp et al. (2005) recognize that in concentrated markets, margins may be high, and firms might be reluctant to diminish these by getting involved in a price war. Ramaswamy et al. (1994) also find that market concentration has a negative impact on the likelihood of price retaliation. Overall, we expect immediate, gross, and net cross-brand elasticities to be greater in more concentrated markets. However, because competitive reactions are less likely, we cannot form a hypothesis about the net price elasticity.

Interpurchase time: Consumers trade off the lower cost of the promoted brand against the substitution cost of buying a less-preferred brand. This cost is not severe in product categories with a short interpurchase time, because the consumer only needs to live with the consequences of his or her decision for a short period and then can switch back to the preferred brand. Therefore, shorter interpurchase times should be associated with increased brand switching caused by promotion (Bawa and Shoemaker 1987, Narasimhan et al. 1996). Furthermore, interpurchase times may be related to purchase acceleration. In particular, long interpurchase times discourage acceleration because the stockpiled product must be stored for a longer period, which increases the consumer's cost of stockpiling (Blattberg et al. 1981). Finally, in categories with higher immediate brand switching, competing brands will be more motivated to retaliate (Steenkamp et al. 2005). Thus, we expect categories

Table 2 Hypotheses on Moderating Factors for Cross-Price Elasticities

\begin{tabular}{lccc}
\hline Variable & Immediate effect & Gross effect & Net effect \\
\hline Asymmetric price effect (Price A > Price V) & + & + & $?$ \\
Neighborhood price effect (Price A - Price V| & - & + & $?$ \\
Asymmetric share effect (Share A > Share V) & + & + & $?$ \\
Neighborhood share effect |Share A - Share V| & - & - & $?$ \\
National brand (A) vs. private label (V) & + & - & $?$ \\
Private label (A) vs. national brand (V) & - & + & $?$ \\
Average price & - & + & $?$ \\
Average size & - & - & + \\
V's relative price promotion frequency & + & - & + \\
V's relative depth of price promotions & + & + \\
V's relative feature and display frequency & $?$ & - \\
A's relative price promotion frequency & - & + \\
A's relative depth of price promotions & - & + \\
A's relative feature and display frequency & + & + \\
Perishability & - & + \\
Utilitarian & + & + \\
Budget share (avg) & + & + \\
Competitive concentration & + & + \\
Interpurchase time & - & $?$ \\
\hline
\end{tabular}

${ }^{a}$ The markets in our data contain one private label maximum, so there are no private label/private label pairs. We choose national/national brand pairs as the base for the private label/national brand asymmetry. The national brand (A) vs. private label $(\mathrm{V})$ variable measures whether the effect of a promotion by a national brand on a private label differs from this base. The private label (A) vs. national brand (V) variable can be interpreted accordingly. 
with shorter consumer interpurchase times to face more brand switching and, therefore, increased immediate and gross effects. However, the increased competitive reactions likely lead to a lower net effect. Whether the effect in the end is positive or negative depends on the reaction intensity of the competitors.

An overall summary of our hypotheses appears in Table 2. Note that in all cases, we expect the same sign for the moderation parameters with respect to the immediate and gross effect. This is because consumer dynamics seem to magnify the moderation of all variables in all cases. Competitive dynamics, however, work against these effects in most cases. Thus, if the competitive reactions are strong enough, they may cancel the moderation effects or even turn them around. This uncertainty is indicated by the question marks in Table 2.

\section{Methodology}

Measuring the impact of moderating variables on the immediate, gross, and net effects of price promotions requires multiple models. Immediate and gross effects only pertain to consumer behavior, so we can measure them using VEC models for sales, conditional on current and lagged prices. To measure the net effect, which also depends on competitive reactions, we also specify VARX models for promotional prices, using lagged sales and lagged promotional prices as explanatory variables. In other words, we model sales and price promotional decisions jointly by specifying the conditional distribution of sales given prices and the marginal distribution of prices. To connect the cross-price promotional effects with moderating variables, we jointly consider the models for all product categories in a hierarchical Bayes fashion. The combination of the models yields our HB-VEC-VARX model.

Cross-price promotional effects are difficult to estimate and thus are often insignificant. Therefore, we measure cross-price promotional elasticities in a large number of product categories in five different stores. Note that across stores, different brands may make up a category, and the positioning of the same brand may differ across stores. Therefore, we treat the categories and their brands in the different stores independently. This approach allows us to connect the moderating factors with a broad sample of cross-price elasticities, thereby improving the generalizability and robustness of our results.

Our model extends the models of Fok et al. (2006) and Van Heerde et al. (2007) in several ways. Van Heerde et al. (2007) examine (time-varying) baseline sales and focus on own and cross effects in one specific market. Fok et al. (2006), whose model is the closest to our approach, only use a conditional model for sales given prices, whereas our model also specifies the marginal model for prices-that is, a set of competitive reaction equations. Furthermore, Fok et al. explicitly focus on own-price effects, whereas we analyze cross-price effects. This requires a major change in the structure of the second-level model. Finally, whereas Fok et al. (2006) use information from one store, we combine data across several stores to establish generalizable and robust results.

\subsection{First-Level Model: Measuring Cross-Price Promotional Effects}

In the first level of our model, we specify a multivariate model for all brands in each store and each category. To simplify the notation, we do not explicitly distinguish between stores; thus we use the word "category" to refer to a store-category combination. Let $C$ be the total number of store-category combinations, and let $I_{c}$ denote the number of brands in category $c$, where $c=1, \ldots, C$. Next, let $S_{c t}$ and $P_{c t}$ denote $I_{c}$-dimensional vectors of sales and promotional prices ${ }^{1}$ for category $c$ in week $t$.

We first specify a model for $S_{c t}$ conditional on $P_{c t}$. Then, we set up the model for $P_{c t}$. Explanatory variables other than the promotional price are collected in the $I_{c}$-dimensional vectors $X_{c k t}$, each containing the $k$ th set of (marketing-mix) variables for the brands in category $c$ in week $t, k=1, \ldots, K$. Note that these vectors also contain regular price variables. For this part of the model, we follow Fok et al. (2006) and specify the following VEC model to explain sales, conditional on promotional prices, for category $c$ (see also Van Heerde et al. 2007, 2010):

$$
\begin{aligned}
\Delta \log S_{c t} \\
=\mu_{c}+A_{c} \Delta \log P_{c t}+\sum_{k=1}^{K} A_{c k}^{*} \Delta X_{c k t} \\
\quad+\Pi_{1 c}\left(\log S_{c, t-1}-B_{c} \log P_{c, t-1}-\sum_{k=1}^{K} B_{c k}^{*} X_{c k, t-1}\right) \\
\quad+\boldsymbol{\varepsilon}_{c t},
\end{aligned}
$$

where $\varepsilon_{c t} \sim \mathrm{N}\left(0, \Sigma_{c}\right)$, for $c=1, \ldots, C, t=1, \ldots, T_{c}$, and $\Delta$ is the first difference operator (for example, $\left.\Delta X_{c k t}=X_{c k t}-X_{c k, t-1}\right)$. The matrix $\Pi_{1 c}$ measures the speed of adjustment of sales to the long-run steady state. The sales are stationary if the eigenvalues of $\mathbf{I}+\Pi_{1 c}$ are within the unit circle, where I denotes a unit matrix. ${ }^{2}$ The matrices $A_{c}$ and $B_{c}$ contain own- and

\footnotetext{
${ }^{1}$ The promotional price refers to the actual price divided by the regular price.

${ }^{2}$ Previous research (e.g., Fok et al. 2006, Horváth et al. 2005, Nijs et al. 2001, Pauwels et al. 2002) has shown that most sales series are (trend) stationary, after correcting for possible seasonality and possible breaks as a result of changes in the regular price series.
} 
cross-brand price effects, with the own effects as diagonal and the cross effects as off-diagonal elements. The element of $A_{c}$ in row $i$ and column $j$, denoted by $A_{i j, c}$, corresponds to the effect of a price promotion by brand $j$ on brand $i$ 's sales in category $c$. Finally, $\mu_{c}$ is a vector of intercepts.

To capture competitive reactions, we augment this model with a marginal model for price, given only lagged information. To this end, we specify a VARX model for promotional prices; that is, for category $c$,

$$
\begin{aligned}
\log P_{c t}= & \delta_{c}+\left(\mathbf{I}+\Pi_{2 c}\right) \log P_{c, t-1}+D_{c} \log S_{c, t-1} \\
& +\sum_{k=1}^{K} D_{c k}^{*} X_{k, c t}+\xi_{c t},
\end{aligned}
$$

where $\xi_{c t} \sim \mathrm{N}\left(0, \Omega_{c}\right)$. Competitive reactions are contained in the matrices $\Pi_{2 c}$ and $D_{c}$; that is, the current price of a brand may depend on lagged sales or lagged prices of another brand. ${ }^{3}$ Conditional on sales and the additional explanatory variables, this model has stationary price paths, as long as the eigenvalues of $\mathbf{I}+\Pi_{2 c}$ are within the unit circle. To match the VEC model for sales, we rewrite this model as

$$
\begin{aligned}
\Delta \log P_{c t}= & \delta_{c}+\Pi_{2 c} \log P_{c, t-1}+D_{c} \log S_{c, t-1} \\
& +\sum_{k=1}^{K} D_{c k}^{*} X_{k, c t}+\xi_{c t} .
\end{aligned}
$$

Although this model is specified for price changes, that does not mean that prices are nonstationary. The model in Equation (3) is completely equivalent to that in Equation (2). Because Equation (3) is the marginal model for prices, the error $\xi_{c t}$ by construction is independent of $\varepsilon_{c t}$.

The models in Equations (1) and (3) together specify the joint model of sales and promotional prices. We write them jointly as

$$
\begin{aligned}
\left(\begin{array}{cc}
\mathbf{I} & -A_{c} \\
0 & \mathbf{I}
\end{array}\right)\left(\begin{array}{l}
\Delta \log S_{c t} \\
\Delta \log P_{c t}
\end{array}\right) \\
=\left(\begin{array}{c}
\mu_{c} \\
\delta_{c}
\end{array}\right)+\left(\begin{array}{cc}
\Pi_{1 c} & -\Pi_{1 c} B_{c} \\
D_{c} & \Pi_{2 c}
\end{array}\right) \\
\cdot\left(\begin{array}{l}
\log S_{c, t-1} \\
\log P_{c, t-1}
\end{array}\right)+\left(\begin{array}{c}
\varepsilon_{c t} \\
\xi_{c t}
\end{array}\right),
\end{aligned}
$$

${ }^{3}$ Note that we exclude the possibility of immediate reactions. In theory, such reactions may be possible for a private label: the retailer knows prices and may adapt the private label's price according to competing promotions. If such reactions occur, they will be reflected in the covariance matrix $\Omega_{c}$. For the empirical analysis, we inspected these matrices and can conclude that direct reactions by the private label are not present in our data. This finding is confirmed by a direct analysis of the contemporaneous correlation between prices. We find that if one brand is for sale, another one is less likely to be promoted in the same period as well. This is in line with the idea of an alternating promotional schedule described in Lal (1990) and Rao et al. (1995). where, for notational convenience, we omit the exogenous variables $\left(X_{k c t}\right)$. This system of equations can be solved to give

$$
\begin{aligned}
\left(\begin{array}{c}
\log S_{c t} \\
\log P_{c t}
\end{array}\right)= & \left(\begin{array}{c}
\mu_{c}+A_{c} \boldsymbol{\delta}_{c} \\
\delta_{c}
\end{array}\right) \\
& +\left(\begin{array}{cc}
\mathbf{I}+\Pi_{1 c}+A_{c} D_{c} & A_{c} \Pi_{2 c}-\Pi_{1 c} B_{c} \\
D_{c} & \mathbf{I}+\Pi_{2 c}
\end{array}\right) \\
& \cdot\left(\begin{array}{cc}
\log S_{c, t-1} \\
\log P_{c, t-1}
\end{array}\right)+\left(\begin{array}{cc}
\mathbf{I} & A_{c} \\
0 & \mathbf{I}
\end{array}\right)\left(\begin{array}{c}
\varepsilon_{c t} \\
\xi_{c t}
\end{array}\right) .
\end{aligned}
$$

\subsection{Immediate, Gross, and Net Effects}

To obtain the immediate and gross effects of a price promotion, we need only to consider Equation (1). It is relatively straightforward to show that $A_{i j, c}$ can be interpreted as the immediate effect, or immediate price elasticity, of brand $j$ on brand $i$. More formally,

$$
\frac{\partial S_{i c t}}{\partial P_{j c t}} \frac{P_{j c t}}{S_{i c t}}=\frac{\partial \log S_{i c t}}{\partial \log P_{j c t}}=A_{i j, c} .
$$

The parameter $B_{i j, c}$ refers to the (cumulative) gross effect of a price promotion of brand $j$ on the present and future sales of brand $i$, assuming that future prices are not affected by the promotion. In terms of partial effects or elasticities, the gross effect equals

$$
\sum_{\tau=0}^{\infty} \frac{\partial S_{i c, t+\tau}}{\partial P_{j c t}} \frac{P_{j c t}}{S_{i c, t+\tau}}=\sum_{\tau=0}^{\infty} \frac{\partial \log S_{i c, t+\tau}}{\partial \log P_{j c t}}=B_{i j, c},
$$

and Fok et al. (2006) provide the derivation.

The derivation of the net effect is more complicated. Because it measures the cumulative immediate and dynamic responses of consumers and competitors to a price promotion, we need the complete model in Equation (5). In this formulation, a price promotion is equivalent to an unexpected change in price at time $t$-that is, a shock to prices through $\xi_{c t}$. The immediate impact of such a shock is $\xi_{c t}$ for prices and $A_{c} \xi_{c t}$ for sales; that is, a shock of size 1 to the log price of brand $j$ leads to a change of size $A_{i j, c}$ in the log sales of brand $i$ (see also Equation (6)). The size of the impact of this shock on sales and prices at time $t+\tau$ is given by

$$
\left(\begin{array}{cc}
\mathbf{I}+\Pi_{1 c}+A_{c} D_{c} & A_{c} \Pi_{2 c}-\Pi_{1 c} B_{c} \\
D_{c} & \mathbf{I}+\Pi_{2 c}
\end{array}\right)^{\tau}\left(\begin{array}{c}
A_{c} \\
\mathbf{I}
\end{array}\right) \xi_{c t} .
$$

The (cumulative) net effect is therefore

$$
\begin{aligned}
& \sum_{\tau=0}^{\infty}\left(\begin{array}{cc}
\mathbf{I}+\Pi_{1 c}+A_{c} D_{c} & A_{c} \Pi_{2 c}-\Pi_{1 c} B_{c} \\
D_{c} & \mathbf{I}+\Pi_{2 c}
\end{array}\right)^{\tau}\left(\begin{array}{c}
A_{c} \\
\mathbf{I}
\end{array}\right) \xi_{c t} \\
& =\left[\mathbf{I}-\left(\begin{array}{cc}
\mathbf{I}+\Pi_{1 c}+A_{c} D_{c} & A_{c} \Pi_{2 c}-\Pi_{1 c} B_{c} \\
D_{c} & \mathbf{I}+\Pi_{2 c}
\end{array}\right)\right]^{-1}\left(\begin{array}{c}
A_{c} \\
\mathbf{I}
\end{array}\right) \xi_{c t}
\end{aligned}
$$




$$
\begin{aligned}
& =\left(\begin{array}{cc}
-\Pi_{1 c}-A_{c} D_{c} & \Pi_{1 c} B_{c}-A_{c} \Pi_{2 c} \\
-D_{c} & -\Pi_{2 c}
\end{array}\right)^{-1}\left(\begin{array}{c}
A_{c} \\
\mathbf{I}
\end{array}\right) \xi_{c t} \\
& =\Gamma_{c} \xi_{c t} .
\end{aligned}
$$

The first equality holds only if the complete system in Equation (5) is stationary. Otherwise, the net effects are equal to plus or minus infinity. Under the assumption of stationarity, the matrix $\Gamma_{c}$ exists and is of dimension $2 I_{c} \times I_{c}$. The upper $I_{c} \times I_{c}$ block of this matrix (denoted by $\Gamma_{c}^{(s)}$ ) contains the total sales responses to an initial price promotion. The lower $I_{c} \times I_{c}$ block (denoted by $\Gamma_{c}^{(p)}$ ) contains the total price responses. More precisely, the $(i, j)$ element of $\Gamma_{c}^{(s)}$ (denoted by $\Gamma_{i j, c}^{(s)}$ ) measures the sum of sales responses by brand $i$ over time to the initial price promotion of brand $j$, and $\Gamma_{i j, c}^{(p)}$ gives the cumulative reactions in the price of brand $i$ due to a promotion by $i$. Therefore, the net cross-price effects are the off-diagonal elements of $\Gamma_{c}^{(s)}$.

\subsection{Second-Level Model: Relating the Cross-Price Promotional Effects to Moderating Variables}

Our main interest is in the cross effects, so for notational efficiency, we collect all cross-price effects for category $c$ in $I_{c} \cdot\left(I_{c}-1\right)$-dimensional vectors. The cross-effect elements from $A_{c}$ are collected in $\tilde{\alpha}_{c}$, the elements from $B_{c}$ in $\tilde{\beta}_{c}$, and the elements from $\Gamma_{c}^{(s)}$ in $\tilde{\gamma}_{c}$. More precisely,

$$
\begin{aligned}
\tilde{\alpha}_{c}= & \left(A_{12, c}, A_{13, c}, \ldots, A_{1 I_{c}, c}, A_{21, c}, A_{23, c}, \ldots,\right. \\
& \left.A_{2 I_{c}, c}, \ldots, A_{I_{c} 1, c}, A_{I_{c} 2, c}, \ldots, A_{I_{c}, I_{c}-1, c}\right)^{\prime} \\
\tilde{\beta}_{c}= & \left(B_{12, c}, B_{13, c}, \ldots, B_{1 I_{c}, c}, B_{21, c}, B_{23, c}, \ldots,\right. \\
& \left.B_{2 I_{c}, c}, \ldots, B_{I_{c} 1, c}, B_{I_{I^{c}}, c}, \ldots, B_{I_{c}, I_{c}-1, c}\right)^{\prime} \\
\tilde{\gamma}_{c}= & \left(\Gamma_{12, c}^{(s)}, \Gamma_{13, c}^{(s)}, \ldots, \Gamma_{1 I_{c}, c}^{(s)}, \Gamma_{21, c}^{(s)}, \Gamma_{23, c}^{(s)}, \ldots,\right. \\
& \left.\Gamma_{2 I_{c}, c}^{(s)}, \ldots, \Gamma_{I_{c} 1, c}^{(s)}, \Gamma_{I_{c} 2, c}^{(s)}, \ldots, \Gamma_{I_{c}, I_{c}-1, c}^{(s)}\right)^{\prime} .
\end{aligned}
$$

Therefore, $\tilde{\alpha}_{c}$ captures all the immediate effects, $\tilde{\beta}_{c}$ all the gross effects, and $\tilde{\gamma}_{c}$ all the net cross-brand price promotional effects in category $c$. Finally, we introduce two functions, $i(l)$ and $j(l)$, that map the index of an element of $\tilde{\alpha}_{c}, \tilde{\beta}_{c}$, or $\tilde{\gamma}_{c}$ to the index of the victim and attacker brands, respectively. For example, $i(2)=1$ and $j(2)=3$, so the second elasticity in $\tilde{\alpha}_{c}$ corresponds to the cross elasticity of brand 3 on brand 1 , as specified in Equation (11).

Differences in the immediate, gross, and net elasticities across brand pairs can partly be attributed to observable characteristics, such as store effects, asymmetry effects, neighborhood effects, and brand- and category-specific variables. Therefore, to describe the immediate, gross, and net elasticity parameters for promotional price, we use

$$
\begin{aligned}
\tilde{\alpha}_{l, c}= & \theta_{0}^{(1)}+\theta_{1}^{(1)^{\prime}} z_{i(l), c}+\theta_{2}^{(1)^{\prime}} z_{j(l), c}+\theta_{3}^{(1)^{\prime}} g\left(z_{i(l), c}, z_{j(l), c}\right) \\
& +\theta_{4}^{(1)^{\prime}} z_{c}+\theta_{5}^{(1)^{\prime}} d_{c}+\eta_{l c}^{(1)}, \\
\tilde{\beta}_{l, c}= & \theta_{0}^{(2)}+\theta_{1}^{(2)^{\prime}} z_{i(l), c}+\theta_{2}^{(2)^{\prime}} z_{j(l), c}+\theta_{3}^{(2)^{\prime}} g\left(z_{i(l), c}, z_{j(l), c}\right) \\
& +\theta_{4}^{(2)^{\prime}} z_{c}+\theta_{5}^{(2)^{\prime}} d_{c}+\eta_{l c}^{(2)}, \\
\tilde{\gamma}_{l, c}= & \theta_{0}^{(3)}+\theta_{1}^{(3)} z_{i(l), c}+\theta_{2}^{(3)^{\prime}} z_{j(l), c}+\theta_{3}^{(3)^{\prime}} g\left(z_{i(l), c}, z_{j(l), c}\right) \\
& +\theta_{4}^{(3)^{\prime}} z_{c}+\theta_{5}^{(3)^{\prime}} d_{c}+\eta_{l c}^{(3)},
\end{aligned}
$$

where $z_{c}$ contains variables on the category level, for example, the competitive concentration of the category; and $z_{i, c}$ is a vector of characteristics of brand $i$ in category $c$. The use of the two mapping functions $i(l)$ and $j(l)$ leads to a model in which the characteristics of both the attacker brand $\left(z_{j(l), c}\right)$ and the victim brand $\left(z_{i(l), c}\right)$ are included. The vector $d_{c}$ contains dummy variables for the different stores. The neighborhood and asymmetric price and sales effects are captured by the function $g()$. In the empirical analysis that follows, $g()$ includes the absolute difference in the overall price level between the attacker and the victim, the absolute difference in their sizes, indicators of whether the attacker brand is larger or more expensive than the victim brand, and the average price and share of the two brands. The parameter vectors $\theta_{n}^{(1)}$, $\theta_{n}^{(2)}$, and $\theta_{n}^{(3)}, n=1, \ldots, 5$, describe the effects of all characteristics on the immediate and dynamic elasticities, where the superscript refers to one of the three effects (immediate, net, or cumulative) and the subscript refers to one of the five model components. For the error terms $\eta_{l, c^{\prime}}^{(1)} \eta_{l, c^{\prime}}^{(2)}$ and $\eta_{l, c^{\prime}}^{(3)}$ we assume independent normal distributions.

\subsection{Estimation}

To estimate the parameters of our model, we consider a Bayesian approach using Markov chain Monte Carlo (MCMC) sampling. A complete Bayesian approach is not feasible, because the net effect constitutes a highly nonlinear combination of many parameters (see Equation (9)). Therefore, we propose another strategy that leads to unbiased estimates. We first obtain posterior draws for the sales and price models for all categories in the first layer of our model, together with the second layer as described in Equations (11) and (12). This gives a complete picture of the immediate and net effects and all competitive reactions.

We use the combination of draws from both sets of models to obtain posterior draws for the net effect, according to Equation (9). These draws are used to provide inference on the moderators of the net effect. In each iteration of the Markov chain for this part of the model, we take a different draw of the net effects as the dependent variable to ensure that we properly 
deal with the uncertainty in the net effects. The full details of the procedure, together with the set of priors used, appear in Appendix A.

\subsection{Simulation Results}

To check the performance of our Bayesian sampler, we test our procedures on simulated data. The simulation design matches our empirical data in size - that is, in terms of the number of store/category combinations $(5 \times 33)$, the number of brands in each category (five), and the number of observations (five years of weekly data).

The experiment is as follows.

Step 1 . We randomly generate brand and category characteristics.

Step 2. We randomly generate all own-price effects.

Step 3. We generate all cross-price effects using the characteristics of the victim and the attacker brand as specified in Equations (11)-(13).

Step 4 . We generate sales and prices for all brands using the generated own and cross effects and the generated values for all other coefficients in the models (see Equation (4)).

Step 5. We calculate the true net cross-price effects using the generated parameters and Equation (9);

Step 6. We apply our model and estimation procedure as presented previously.

Note that in this simulation, we generate the ownprice effects as a function of the brand characteristics, but in our estimation procedure, we ignore this dependence. We use our simulation experiment not only to check the performance of the MCMC algorithm but also to confirm that we can safely ignore the dependence of own effects on brand and category characteristics when analyzing the moderating factors for cross effects. ${ }^{4}$

In Step 1, we generate two continuous category variables (e.g., competitive concentration and budget share), one binary brand variable (e.g., a private label indicator), and one continuous brand variable (e.g., promotional frequency). We generate the continuous variables from a standard normal distribution. The binary variable is set to 1 for one of the brands in each category. The own effects are moderated by all characteristics; that is, they are generated according to

$$
\begin{aligned}
& A_{i i, c}=\lambda_{0}^{(1)}+\lambda_{1}^{(1)^{\prime}} z_{i, c}+\lambda_{2}^{(1)^{\prime}} z_{c}+\zeta_{i c}^{(1)}, \\
& B_{i i, c}=\lambda_{0}^{(2)}+\lambda_{1}^{(2)^{\prime}} z_{i, c}+\lambda_{2}^{(2)^{\prime}} z_{c}+\zeta_{i c}^{(2)},
\end{aligned}
$$

where $A_{i i, c}$ and $B_{i i, c}$ are the immediate and gross own-price effects, respectively, as defined in Equation (1). The vector $z_{i, c}$ denotes the characteristics of

\footnotetext{
${ }^{4}$ Intuition indicates that omitting moderators of the own effects should not bias the results of the moderators of the cross effects. The simulation results in this section confirm this. We thank a reviewer for suggesting this point.
}

brand $i$ in category $c, z_{c}$ denotes a vector of characteristics of category $c$, and $\zeta_{i c}^{(1)}$ and $\zeta_{i c}^{(2)}$ are independently normal distributed random effects. ${ }^{5}$ We set the cross effects such that they depend on the brand characteristics of the victim and the attacker and on the first category variable. We deliberately set the impact of the second category variable to 0 . This means that this variable only affects the own-price effects. The chosen parameter values for these moderating effects appear in the second column of Table 3. The level of the variance of the random effect is set to match our empirical results. The parameter values for the moderators on the net effect cannot be set directly. The net effects follow from the immediate and gross cumulative effects in combination with the competitive reactions (see Equation (9)). Therefore, the impact of the moderators on the net effects is a result of the chosen values for the other parameters. We obtain the reported true values for the net effect in Table 3 by regressing the true cross-price net effects on the moderating variables.

Table 3 also shows the posterior means, posterior standard deviations, and $90 \%$ highest posterior density (HPD) regions for all cross-price parameters, obtained using our Bayesian procedure. It is clear that parameter recovery is excellent. All posterior means are close to the true values, and for almost all parameters, the true value is contained in the $90 \%$ HPD region. Thus, ignoring the impact of the moderators on the own effects does not lead to a bias in the cross effects. Moreover, although the second-category variable only affects the own-price effects, we do not spuriously find a moderating effect of this variable on the cross effects.

\section{Empirical Results}

\subsection{Data and Variables}

For our empirical analysis, we use data on five stores, gathered from the recently released Information Resources Inc. (IRI) data set (Bronnenberg et al. 2008). This data set contains five years of data on 31 main product categories across many U.S. supermarkets. ${ }^{6}$ We selected the five stores using the following criteria: (1) the size of the store, measured using

\footnotetext{
${ }^{5}$ The chosen parameter values for the immediate own effect are as follows: intercept, -1.2 ; binary brand variable, -0.2 ; continuous category variable $1,0.1$; continuous category variable $2,-0.4$; and continuous brand variable, -0.2 . For the cumulative own effects, we set these parameter values equal to $-0.75,-0.1,-0.1,-0.2$, and 0.2 , respectively.

${ }^{6}$ The categories are labeled as follows: beer, blades, carbbev, cigets, coffee, coldcer, deod, diapers, factiss, fzdinent, fzpizza, hhclean, hotdog, laundet, margbutr, mayo, milk, mustketc, paptowl, peanbutr, photo, razors, saltsnck, shamp, soup, spagsauc, sugarsub, toitisu, toothbr, toothpa, and yogurt.
} 
Table 3 Estimation Results on Moderators of Cross-Price Effects Using Simulated Data for 165 Markets, Where Each Market Contains Five Brands (Total of 3,300 Cross Effects)

\begin{tabular}{|c|c|c|c|c|}
\hline & True value $^{\mathrm{a}}$ & Posterior mean & Posterior SD & $90 \%$ HPD region \\
\hline \multicolumn{5}{|c|}{ Immediate cross-promotional price effect } \\
\hline Intercept & 0.1 & 0.099 & $(0.003)^{* * *}$ & {$[0.094,0.103]$} \\
\hline Binary brand variable $(\mathrm{V})$ & 0.1 & 0.102 & $(0.005)^{* * *}$ & {$[0.092,0.11]$} \\
\hline Binary brand variable $(A)$ & -0.15 & -0.148 & $(0.005)^{* * *}$ & {$[-0.157,-0.14]$} \\
\hline Continuous category variable 1 & 0.1 & 0.100 & $(0.003) * * *$ & {$[0.095,0.106]$} \\
\hline Continuous category variable 2 & 0 & -0.002 & $(0.003)$ & {$[-0.007,0.002]$} \\
\hline Continuous brand variable $(\mathrm{V})$ & 0.05 & 0.050 & $(0.002)^{* * *}$ & {$[0.047,0.054]$} \\
\hline Continuous brand variable $(A)$ & -0.05 & -0.048 & $(0.002)^{* * *}$ & {$[-0.052,-0.045]$} \\
\hline Variance of error & 0.01 & 0.011 & $(0.000)^{* * *}$ & {$[0.01,0.011]$} \\
\hline \multicolumn{5}{|c|}{ Gross cumulative cross-promotional price effect } \\
\hline Intercept & 0.2 & 0.190 & $(0.004)^{* * *}$ & {$[0.184,0.197]$} \\
\hline Binary brand variable $(\mathrm{V})$ & 0.15 & 0.151 & $(0.008)^{* * *}$ & {$[0.138,0.164]$} \\
\hline Binary brand variable $(A)$ & -0.1 & -0.090 & $(0.008)^{* * *}$ & {$[-0.102,-0.077]$} \\
\hline Continuous category variable 1 & 0.15 & 0.148 & $(0.005)^{* * *}$ & {$[0.14,0.156]$} \\
\hline Continuous category variable 2 & 0 & -0.001 & $(0.004)$ & {$[-0.009,0.006]$} \\
\hline Continuous brand variable (V) & 0.05 & 0.053 & $(0.003)^{* * *}$ & {$[0.048,0.058]$} \\
\hline Continuous brand variable $(A)$ & -0.03 & -0.028 & $(0.003)^{* * *}$ & {$[-0.033,-0.023]$} \\
\hline Variance of error & 0.01 & 0.011 & $(0.001)^{* * *}$ & {$[0.01,0.012]$} \\
\hline \multicolumn{5}{|c|}{ Net cumulative cross-promotional price effect } \\
\hline Intercept & 0.294 & 0.277 & $(0.009)^{* * *}$ & {$[0.263,0.291]$} \\
\hline Binary brand variable $(\mathrm{V})$ & 0.194 & 0.190 & $(0.018)^{* * *}$ & {$[0.16,0.22]$} \\
\hline Binary brand variable $(A)$ & -0.155 & -0.133 & $(0.017)^{* * *}$ & {$[-0.16,-0.106]$} \\
\hline Continuous category variable 1 & 0.216 & 0.213 & $(0.010)^{* * *}$ & {$[0.197,0.23]$} \\
\hline Continuous category variable 2 & -0.003 & -0.007 & $(0.009)$ & {$[-0.022,0.008]$} \\
\hline Continuous brand variable $(\mathrm{V})$ & 0.075 & 0.077 & $(0.007)^{* * *}$ & {$[0.066,0.088]$} \\
\hline Continuous brand variable $(\mathrm{A})$ & -0.046 & -0.043 & $(0.006)^{* * *}$ & {$[-0.054,-0.033]$} \\
\hline Variance of error & 0.061 & 0.090 & $(0.004)^{* * *}$ & {$[0.083,0.097]$} \\
\hline
\end{tabular}

${ }^{\text {aThe }}$ "true values" for the net cumulative effect are not set directly in the simulation design. The reported values are obtained by regressing the true net cumulative cross-price effects on the moderating variables.

${ }^{* * *} 99 \%$ HPD regions do not contain zero; ${ }^{* *} 95 \%$ HPD regions do not contain zero; $* 90 \%$ HPD regions do not contain zero.

the all commodity volume (we chose average-sized stores), (2) opening and closing dates (stores opening or closing during the five years of data are excluded), (3) sufficient variation in price, and (4) availability of categories (the stores must have at least two brands in all product categories). We randomly selected five stores out of all qualifying stores. The restriction to "just" five stores is due to computing time and computer memory limitations.

Before aggregating the data to the brand level, we select the focal stockkeeping units (SKUs). Some of the IRI-defined categories actually contain different types of products, whereas we adopt a narrow definition of product category. For example, the IRI beer category contains malt beverages, but we ignore all SKUs that are not strictly beer. Other IRI product categories can even be split in two; for example, the IRI mayo category contains data on mayonnaise, salad dressings, and sandwich spreads; and the sandwich spread subcategory is large enough to be considered as a separate category. We also split the carbbev category into colas and other soft drinks, fzdinent into frozen dinners and frozen entrees, and mustketc into mustards and ketchups. Finally, we ignore the photo category (photographic film) because the SKUs are extremely difficult to compare in terms of the number of photos that correspond to a particular SKU. We also exclude the milk category because sometimes this category contains only one brand. In total, we use 33 product categories in five stores.

To aggregate SKU data to the brand level, we use weights. For example, the display variable we construct denotes the percentage of sales generated by SKUs on display. ${ }^{7}$ After aggregation, we delete any brand with an average market share below $1 \%$. Some remaining brands lack data for some weeks, and we use three strategies to deal with these missing

\footnotetext{
${ }^{7}$ This procedure makes the display variable a function of the dependent variable, thus potentially leading to an endogeneity problem. However, endogeneity is likely to be limited because the display variable is actually a function of the SKU shares within a brand, not the actual sales level of the brand (which is the dependent variable in our sales model). Furthermore, such a weighting scheme is common in the literature (see, for example, Leeflang and Wittink 1992, 1996). Some authors opt to have constant weights for the aggregation of promotions-that is, using average volume shares over a long time period (Pauwels 2004). For the aggregation of product-level prices, many authors use brand-level dollar sales divided by the total volume sales (see, for example, Bronnenberg et al. 2000). Note that this is equivalent to a volume share-weighted average of product prices, where the weights vary over time.
} 
values. First, if the corresponding brand has a market share below $5 \%$, we ignore this brand. Second, if the missing values occur at the start or end of the observational period, we remove the initial or final observations for the entire category. Third, we impute any remaining missing values using time averages. The final number of brands per category varies from 2 to 11, and the average category contains five brands. In total, we have 824 brands and 3,950 cross-brand pairs.

We specify error correction models as in Equation (1) for the sales, given promotional and regular prices, display and feature, for each category in each store. ${ }^{8}$ For feature and display, we treat all types of promotions, as defined in the data set, equally. To control for product introductions or deletions in the category, we include the number of unique products sold by each brand as additional explanatory variables (see Appendix B for details on how this variable is constructed). We also include a trend and, if necessary, seasonal dummies, similar to Steenkamp et al. (2005). This method yields 165 error correction models. For each market we also specify a VARX model for the prices. For these models, we also use seasonal dummies, a trend, and the number of unique products sold as additional explanatory variables.

The models are linked by the second-level equations that describe the price effects. As moderating factors of the cross-price elasticities, we include the average price level, defined as the average of the regular prices of the attacker and the victim, relative to the category. We also compute neighborhood and asymmetric price effects on the basis of the average regular prices relative to the category. The average share, neighborhood, and asymmetric share effects are based on the average shares of the attacker and victim brands. We code the effect of private labels using two dummy variables equal to 1 if the victim or the attacker is a private label, respectively. The frequency of price promotions is the frequency of weeks in which the promotional price index fell below 0.9. The average depth of the price promotions reflects the average of the promotional price index, divided by price promotion frequency. Both frequency and depth of price promotions are relative to the market. Experts coded each product category on perishability and utilitarian nature on seven-point scales, where 7 means highly perishable or highly utilitarian. $^{9}$ To operationalize the budget share, we calculate the average expenditure in each category. We

\footnotetext{
${ }^{8}$ We adapted the algorithm of Fok et al. (2006) to decompose the actual price into a regular price variable and a promotional price index.

${ }^{9}$ The scores are not listed to save space, but they are available from the authors upon request.
}

measure competitive concentration using an entropybased measure equal to the sum over all brands of the average market share times the log of the average market share (Raju 1992). We calculate the average interpurchase time using the household-level scanner data that also appear in the IRI database. Because the household-level data are not available for all markets, we average the interpurchase time over all available markets. Finally, we include dummy variables to code the different stores, which permits the overall level of cross effects to differ across stores. We construct these dummies such that they indicate the deviation with respect to the average store; that is, we mean center these dummies.

To facilitate the comparison of effect sizes, we standardize all characteristics except the dummy variables coding the private labels. We perform this standardization before calculating the asymmetry and neighborhood variables.

\subsection{Estimation Results}

We use the Bayesian procedure outlined in Appendix A to obtain insight into the parameter values. The posterior results are based on 100,000 draws, with the first 50,000 as burn-in. To remove correlation in the chain, we consider every fifth draw when computing the posterior results.

4.2.1. Convergence. To test the convergence of the Bayesian procedure, we apply the Geweke (1992) test to the parameters of the moderating variables. In total, we have 72 such parameters. For each parameter, we compare the posterior mean obtained from the first part of the draws with the mean from the final part of the draws. The combination of this test and visual inspection of convergence plots indicate parameter convergence. ${ }^{10}$

4.2.2. Model Fit. Although our model is not predictive, we can use predictive accuracy to assess its quality. So, for each brand in each category, we calculate one-step-ahead predictions for log sales and compare the ratio of the variance of these predictions with the variance in actual log sales. The resulting measure is comparable to the $R^{2}$ measure. For approximately $1.2 \%$ of all 824 brands, this measure is less than 0.25 . For approximately $8 \%$, it falls between 0.25 and 0.50 , and for approximately $30 \%$, the percentage explained variance is between $50 \%$ and $75 \%$. For the remaining $60 \%$, more than $75 \%$ of the variance is explained by our model. These results signal that our models fit the product categories well.

4.2.3. First-Level Results: The Cross-Price Promotional Elasticities. In Table 4 and Figure 2, we summarize the results for all individual cross-price

${ }^{10}$ The actual plots are not included for space considerations but are available from the authors upon request. 


\begin{tabular}{|c|c|c|c|c|c|}
\hline & Immediate effect (\%) & Gross cumulative (\%) & Net cumulative (\%) & $\begin{array}{l}\text { Gross cumulative - } \\
\text { Immediate (\%) }\end{array}$ & $\begin{array}{c}\text { Net }- \text { Gross } \\
\text { cumulative (\%) }\end{array}$ \\
\hline Negative & 20.94 & 17.22 & 24.96 & 39.97 & 41.34 \\
\hline Positive & 79.06 & 82.78 & 75.04 & 60.03 & 58.66 \\
\hline Negative and significant at $99 \%$ & 0.15 & 0.00 & 0.08 & 0.28 & 0.05 \\
\hline Negative and significant at $95 \%-99 \%$ & 0.20 & 0.18 & 0.38 & 0.46 & 0.38 \\
\hline Negative and significant at $90 \%-95 \%$ & 0.48 & 0.28 & 0.51 & 0.73 & 0.58 \\
\hline Negative and not significant at $90 \%$ & 20.10 & 16.76 & 24.00 & 38.51 & 40.33 \\
\hline Positive and not significant at $90 \%$ & 45.97 & 49.22 & 55.06 & 58.03 & 58.03 \\
\hline Positive and significant at $90 \%-95 \%$ & 6.15 & 7.49 & 6.08 & 1.19 & 0.41 \\
\hline Positive and significant at $95 \%-99 \%$ & 9.77 & 9.59 & 7.16 & 0.53 & 0.18 \\
\hline Positive and significant at $99 \%$ & 17.16 & 16.48 & 6.73 & 0.28 & 0.05 \\
\hline
\end{tabular}

Note. "Significant at $x \%$ " should be read as zero is not contained in the $x \%$ HPD region.

effects. Most immediate cross-price effects are positive (i.e., $79 \%$ of 3,950 cases), and approximately 33\% are significantly greater than 0 (see Table 4 ). The few negative effects are relatively small in size and mostly insignificant. Note that negative cross-price effects are present in the literature. A promotion of a brand might sometimes remind some customers about the category, and instead of buying the promoted brand, they buy their strongly preferred, unpromoted brand (Van Heerde et al. 2003).
For the gross effects, we find that the number of negative elasticities decreases when we also account for consumer dynamics, which also holds for the number of negative and significant elasticities. For greater understanding of how consumer dynamics alters cross-promotional effects, we calculate the percentage of cases in which the posterior mean of the gross effect less the immediate effect is positive (see the fifth column of Table 4 and Figure 2(d)). We find that in $60 \%$ of the cases, the gross effect is larger

\section{Figure 2 Histograms of the Posterior Means of the Cross-Price Effects}

(a) Immediate effect

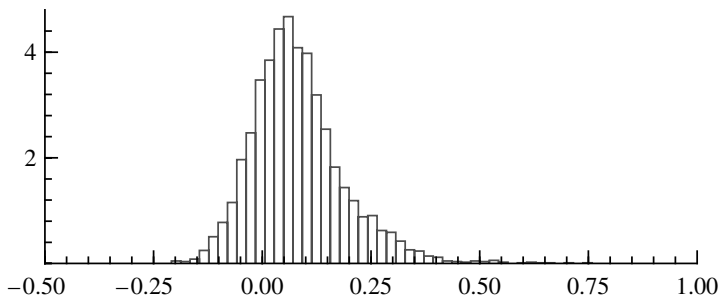

(c) Net cumulative effect

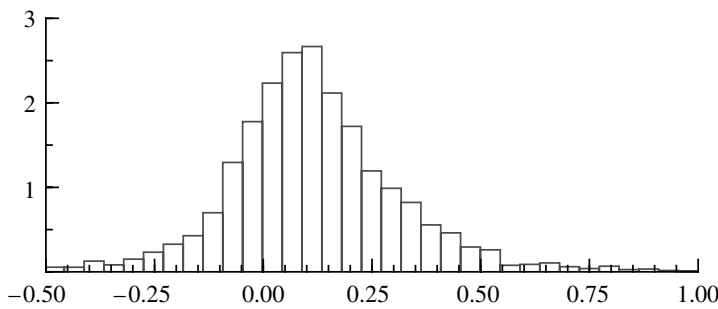

(b) Gross cumulative effect

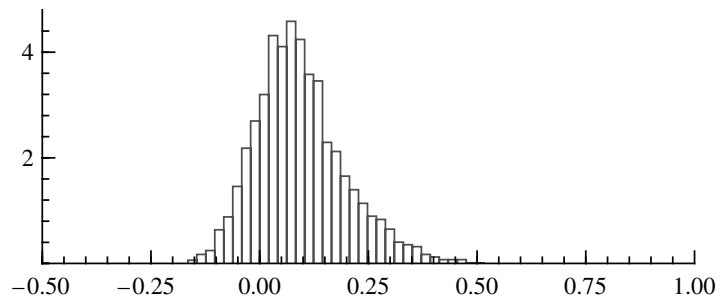

(d) Gross cumulative - Immediate effect

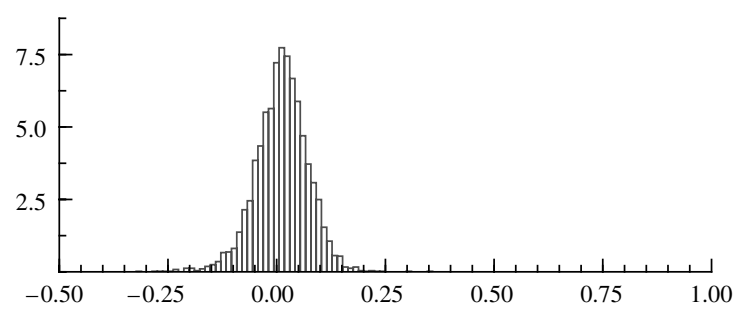

(e) Net - Gross cumulative effect

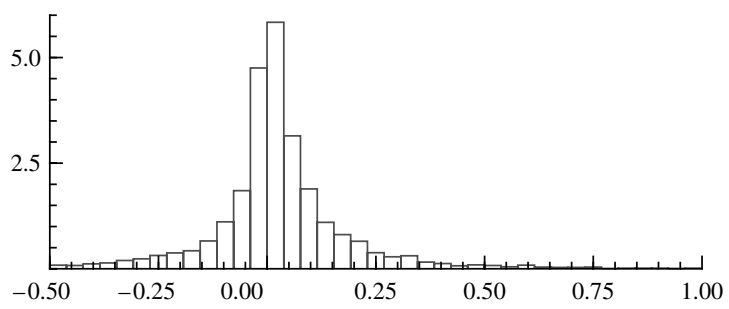

Notes. The horizontal axis for net effects is trimmed to allow for easy comparison. Less than $1.5 \%$ of the net cumulative cross-price effects is cut off. 
than the immediate effect. A straightforward sign test shows that this percentage is significantly different from $50 \%$, the value that corresponds to an absence of a cross-brand post-promotion dip. More precisely, given 3,950 estimated cross effects, the $95 \%$ interval for the percentage of positive findings under the null hypothesis of no cross-brand dip runs from $48.4 \%$ to $51.57 \%$ and does not contain our empirical result $(60 \%)$. Overall, our results suggest that promotions induce customers not only to switch to the discounted brand but also to stockpile it, depressing future competitive sales.

To understand the importance of the cross-brand post-promotion dip, we calculated two measures. First, we calculated the size of the post-promotion dip relative to the immediate cross effect. Second, we calculated the ratio of the average crossbrand post-promotion dip to the average own-brand post-promotion dip. In the second calculation, we corrected for the notion that the two dips were calculated with respect to different brands and that these brands may differ in size. We use the ratio of the average effects across all brands when calculating both measures. We find that, on average, the crossbrand post-promotion dip is approximately $13 \%$ of the immediate cross effect. This means that if brand A takes 100 units away from brand B in the immediate period, it takes another 13 in future periods. We also find that, on average, the cross-brand post-promotion dip is approximately $25 \%$ of the own cross-promotion dip. So if the own-brand post-promotion dip of brand A is 100 units, the cross-brand post-promotion dip will be 25 .

The histogram of the net effects (Figure 2(c)) shows an increased dispersion of the cross effects compared with the distribution of the immediate and gross effects. This outcome and the reduced number of significant elasticities may be due to the increased complexity involved in estimating net effects. The net effects contain dynamic consumer and competitive behavior. Therefore, estimation uncertainty may have a greater impact on the net effect. Moreover, a price promotion by an attacker brand probably induces several competitors to react, so the net effect captures (possible) competitive reactions from all brands, not only the specified victim brand. Yet, the majority of the posterior means remain positive. We find a positive net impact for approximately $75 \%$ of the brand combinations, though of all net cross-price effects, only $20 \%$ are significantly different from 0 . To measure the incremental effect of competitive dynamics on cross-brand effects, we calculate the difference between the net and gross effects, which is positive in $59 \%$ of cases.

Our sign test indicates that this percentage is also significantly different from $50 \%$. So, in general, competitive reactions lead to an increase in the cross effects. At first glance, this is a surprising result, because we might expect competitors to retaliate against a promotion to make up for sales losses. However, the literature provides several potential explanations for this finding. First, both Pauwels (2004) and Steenkamp et al. (2005) show that competitive reactions are as likely to be accommodating as retaliatory. Second, a promotion may induce several brands' reactions at the same time, and these simultaneous responses may further reduce the victim's sales in future periods. Finally, company inertia or retailer dynamic support may cause the initial promotion itself to last for more weeks (Pauwels 2004, 2007).

4.2.4. Second-Level Results: Moderating Factors of Cross-Brand Promotional Effects. Table 5 presents the findings from the second layer of our model, which indicate which moderating factors explain the cross effects for promotional price. The second column contains the results for the immediate, the third for the gross, and the fourth for the net effects. We graphically present these estimates in Figure 3 to illustrate the relative importance of the moderating factors and to show how this is modified by consumer and competitive dynamics.

Recall that all brand and category characteristics, except the dummy variables, are standardized. Thus, the parameter values can be compared and the intercept interpreted as the mean effect across all brand combinations when the size and price of the attacker and the victim brands are equal and both brands are national brands. The asymmetry variables are all dummy variables, so the parameter values are straightforward to interpret. The neighborhood price (share) parameter indicates the difference in cross effect when comparing a case with equal prices (shares) with a case in which the prices (shares) are one standard deviation apart. For the brand-specific variables, the parameter gives the change in cross effect when moving from an "average" brand to a brand that is one standard deviation above the mean on a certain variable. The category-specific variables have a similar interpretation.

The only asymmetry that requires further computation is the national brand/private label asymmetry. This can be calculated from the parameter estimates for the national brand $(\mathrm{A}) /$ private label $(\mathrm{V})$ and the private label $(\mathrm{A}) /$ national brand $(\mathrm{V})$ dummies presented in Table 5 .

Our database contains a maximum of one private label brand in each category. We can therefore only measure cross-price promotional effects for pairs of national brands $(\mathrm{NB}(\mathrm{A}) / \mathrm{NB}(\mathrm{V}))$, for the impact of a national brand on a private label $(\mathrm{NB}(\mathrm{A}) / \mathrm{PL}(\mathrm{V}))$, and for the impact of a private label on a national brand $(\mathrm{PL}(\mathrm{A}) / \mathrm{NB}(\mathrm{V}))$. As said, we code the effect of private labels using two dummy variables, one equal 
Posterior Means (and Standard Deviations) for Moderators of the Cross-Price Effects

\begin{tabular}{|c|c|c|c|}
\hline & Immediate effect & Gross cumulative effect & Net cumulative effect \\
\hline Intercept & $0.072(0.008)^{* * *}$ & $0.090(0.010)^{* * *}$ & $0.118(0.025)^{* * *}$ \\
\hline Asymmetric price effect (Price A > Price V) & $0.050(0.006)^{* * *}$ & $0.045(0.008)^{* * *}$ & $0.058(0.017)^{* * *}$ \\
\hline Neighborhood price effect (|Price V - Price A|) & $-0.024(0.003)^{* * *}$ & $-0.025(0.004)^{* * *}$ & $-0.033(0.008)^{* * *}$ \\
\hline Asymmetric share effect (Share A > Share V) & $0.062(0.007)^{* * *}$ & $0.058(0.009)^{* * *}$ & $0.051(0.020)^{* *}$ \\
\hline Neighborhood share effect (|Share V - Share A|) & $-0.023(0.004)^{* * *}$ & $-0.025(0.006)^{* * *}$ & $-0.028(0.013)^{* *}$ \\
\hline National brand (A) vs. private label (V) & $0.140(0.009)^{* * *}$ & $0.155(0.013)^{* * *}$ & $0.198(0.029)^{* * *}$ \\
\hline Private label (A) vs. national brand (V) & $0.024(0.009)^{* * *}$ & $0.031(0.012)^{* *}$ & $0.039(0.026)$ \\
\hline $\begin{array}{l}\text { Average price level } \\
\text { Average share }\end{array}$ & $\begin{array}{l}0.010(0.005)^{* *} \\
0.068(0.009)^{* * *}\end{array}$ & $\begin{array}{l}0.018(0.006)^{* * *} \\
0.076(0.011)^{* * *}\end{array}$ & $\begin{array}{l}0.021(0.013) \\
0.098(0.025)^{* * *}\end{array}$ \\
\hline $\begin{array}{l}\text { V's relative price promotion frequency } \\
\text { V's relative depth of price promotions } \\
\text { V's relative frequency of display or feature }\end{array}$ & $\begin{array}{l}0.017(0.005)^{* * *} \\
-0.001(0.003) \\
-0.006(0.005)\end{array}$ & $\begin{array}{r}0.015(0.006)^{* *} \\
0.000(0.005) \\
-0.006(0.006)\end{array}$ & $\begin{array}{r}0.026(0.017) \\
0.003(0.012) \\
-0.023(0.016)\end{array}$ \\
\hline $\begin{array}{l}\text { A's relative price promotion frequency } \\
\text { A's relative depth of price promotions } \\
\text { A's relative frequency of display or feature }\end{array}$ & $\begin{array}{r}-0.028(0.005)^{* * *} \\
-0.029(0.006)^{* * *} \\
0.013(0.005)^{* * *}\end{array}$ & $\begin{array}{r}-0.025(0.006)^{* * *} \\
-0.020(0.008)^{* *} \\
0.012(0.007)^{*}\end{array}$ & $\begin{array}{r}-0.032(0.016)^{* *} \\
-0.021(0.016) \\
0.008(0.015)\end{array}$ \\
\hline $\begin{array}{l}\text { Perishability } \\
\text { Utilitarian } \\
\text { Budget share } \\
\text { Competitive concentration } \\
\text { Interpurchase time (avg) }\end{array}$ & $\begin{array}{r}-0.005(0.005) \\
0.002(0.004) \\
-0.003(0.004) \\
0.007(0.005) \\
-0.012(0.005)^{* *}\end{array}$ & $\begin{array}{r}-0.009(0.006) \\
0.001(0.005) \\
0.009(0.006) \\
0.013(0.006)^{* *} \\
-0.016(0.006)^{* *}\end{array}$ & $\begin{array}{r}-0.014(0.014) \\
-0.008(0.011) \\
0.010(0.011) \\
0.027(0.012)^{* *} \\
-0.013(0.014)\end{array}$ \\
\hline $\begin{array}{l}\text { Store } 1 \text { vs. average } \\
\text { Store } 2 \text { vs. average } \\
\text { Store } 3 \text { vs. average } \\
\text { Store } 4 \text { vs. average }\end{array}$ & $\begin{array}{r}0.035(0.008)^{* * *} \\
-0.022(0.009)^{* *} \\
0.052(0.008)^{* * *} \\
-0.018(0.008)^{* *}\end{array}$ & $\begin{array}{r}0.007(0.011) \\
-0.047(0.012)^{* * *} \\
0.034(0.012)^{* * *} \\
-0.010(0.010)\end{array}$ & $\begin{aligned}-0.017(0.021) \\
-0.077(0.024)^{* * *} \\
0.006(0.022) \\
-0.015(0.023)\end{aligned}$ \\
\hline Error variance $\left(\sigma_{\eta^{(n)}}^{2}\right)$ & $0.007(0.0004)^{* * *}$ & $0.007(0.0005)^{* * *}$ & $0.106(0.0428)^{* * *}$ \\
\hline
\end{tabular}

${ }^{* * *} 99 \%$ HPD region does not contain zero; ${ }^{* *} 95 \%$ HPD region does not contain zero; $* 90 \%$ HPD region does not contain zero.

to 1 if the victim is a private label (dummy 1) and the other equal to 1 if the attacker is a private label (dummy 2). According to our coding, the parameters of both dummies have to be interpreted relative to the base scenario $\mathrm{NB}(\mathrm{A}) / \mathrm{NB}(\mathrm{V})$. Dummy 1 therefore captures the difference between $\mathrm{NB}(\mathrm{A}) / \mathrm{PL}(\mathrm{V})$ and $\mathrm{NB}(\mathrm{A}) / \mathrm{NB}(\mathrm{V})$. It measures how much more (or less) national brands take away from private labels than from other national brands. Dummy 2 captures the $\mathrm{PL}(\mathrm{A}) / \mathrm{NB}(\mathrm{V})$ versus $\mathrm{NB}(\mathrm{A}) / \mathrm{NB}(\mathrm{V})$ difference. This measures how much more private labels take away from national brands than other national brands do. The $\mathrm{NB}(\mathrm{A}) / \mathrm{PL}(\mathrm{V})$ versus $\mathrm{PL}(\mathrm{A}) / \mathrm{NB}(\mathrm{V})$ asymmetrythat is, how much more national brands take away

Figure 3 Relative Importance of Moderating Factors for Immediate, Gross Cumulative, and Net Price Promotional Elasticities




from private labels than the other way around-is the difference between the parameters belonging to the two dummies. ${ }^{11}$

The national brand (A)/private label (V) dummy is positive and high; it is 0.140 for the immediate effect. This means that the price promotion of a national brand has a significantly greater immediate impact on a competing private label's sales than on another national brand's performance. We also find a positive and significant, but much smaller, parameter $(0.024)$ belonging to the private label (A)/national brand (V) dummy with respect to the immediate effect. According to this result, private labels take away more from national brands than other national brands do. Private label/national brand asymmetry will be the difference of these two parameters; that is, $0.140-0.024=0.116$. We then can calculate the gross and net effects for the private label/national brand asymmetry correspondingly. Figure 3 contains our calculation of the private label/national brand asymmetry.

Subsequently, we provide some general comments on the results. Next, we answer the questions we raised in the introduction.

Table 5 shows that many of the variables do moderate the cross-promotional price effect. We find most significant estimates for the immediate effect. Comparing all significant parameter estimates with our hypotheses presented in Table 2, we find that almost all signs are in line with our expectations. Surprisingly, if the attacker is a private label, the cross effect tends to be significantly larger instead of smaller as we hypothesized. This indicates that, ceteris paribus, the sales effect of a price promotion of a private label on a national brand is stronger than that of a national brand. This result might be explained by the retailer's power in supplementing private labels' price promotions with additional in-store marketing that draws customers' attention.

The final row of Table 5 provides the variances of the error terms for the cross-price effects. We can explain a relatively large part of the variation in the immediate and the gross cross effects, but for the net effects, we cannot. The size of the variance should be judged relative to the observed variation in the price effects, as Figure 2 shows.

Do the (immediate) asymmetric and neighborhood effects prevail when we simultaneously consider them in one model? Our findings confirm previous results for asymmetric and neighborhood price effects, market share asymmetry, and national brand/private label asymmetry, even if all these effects jointly appear in one model and we control for consumer

\footnotetext{
${ }^{11}$ For further insights about the use and interpretation of dummy variables in the case of a polytomous variable, i.e., a qualitative variable with multiple categories, see, e.g., Fox (2008, p. 124).
}

dynamics, competitive reactions, and brand- and category-specific factors. In addition, we find that not only the relative but also the absolute positioning (especially the average size) of the two brands has a significant influence on the immediate cross-price promotional elasticities. The positive parameter of the average share variable suggests more intense brand switching between two large brands than between small ones. This is a rather surprising result in light of previous literature. An explanation may be that large brands tend to have broad target groups, whereas small brands with a smaller target segment deliver products that are more customized. Brands offering customized products usually have more loyal customers. Fornell (1992) comes to similar conclusions when considering heterogeneity in consumer tastes. He argues that, on average, for customers of smaller firms the distance between the ideal product and the actual product offering is much smaller than that for larger firms. Accordingly, customers of larger firms are, on average, less satisfied than customers of smaller firms and thus also less loyal. Furthermore, large brand pairs are more likely to overlap more in their customer base than smaller brands, which may also lead to more intense brand switching.

Which asymmetric and neighborhood effects are the strongest? Figure 3 clearly shows that the national brand (A)/private label (V) asymmetry is by far the strongest moderator. This holds for the immediate effect as well as for the gross and net effects. The asymmetric price and share effects are the next most important. The neighborhood share and the neighborhood price effects are relatively small. However, these neighborhood effects are still more important than any of the category variables. For easier interpretation of the combined asymmetric and neighborhood effects, we graphically depict the impact of the difference in size or share on the three cross-promotional price elasticities in Figure 4.

The horizontal axis of the plot in, for example, the upper left block shows the relative price positioning of the attacker and victim brands, and the vertical axis shows the contribution of the neighborhood and asymmetric price effect to the immediate crossprice elasticities. Again, a difference of 1 in "price" means that the regular prices are one standard deviation apart. The asymmetric price and share effects are clearly more influential than the neighborhood effects. As the upper left block shows, if the attacker is priced higher than the victim brand, it will have a substantially greater effect on the victim's sales than if it was priced lower. According to the neighborhood effect, this effect disappears if the two brands are priced farther apart. However, for the neighborhood price effect to compensate for the asymmetric price effect, the two brands should be priced far apart, with a price difference of at least 1.5 to 2 standard 
Figure 4 Contribution of Neighborhood and Asymmetric Effects for Price and Size to the Cross-Price Effects, Together with the 90\% HPD Region
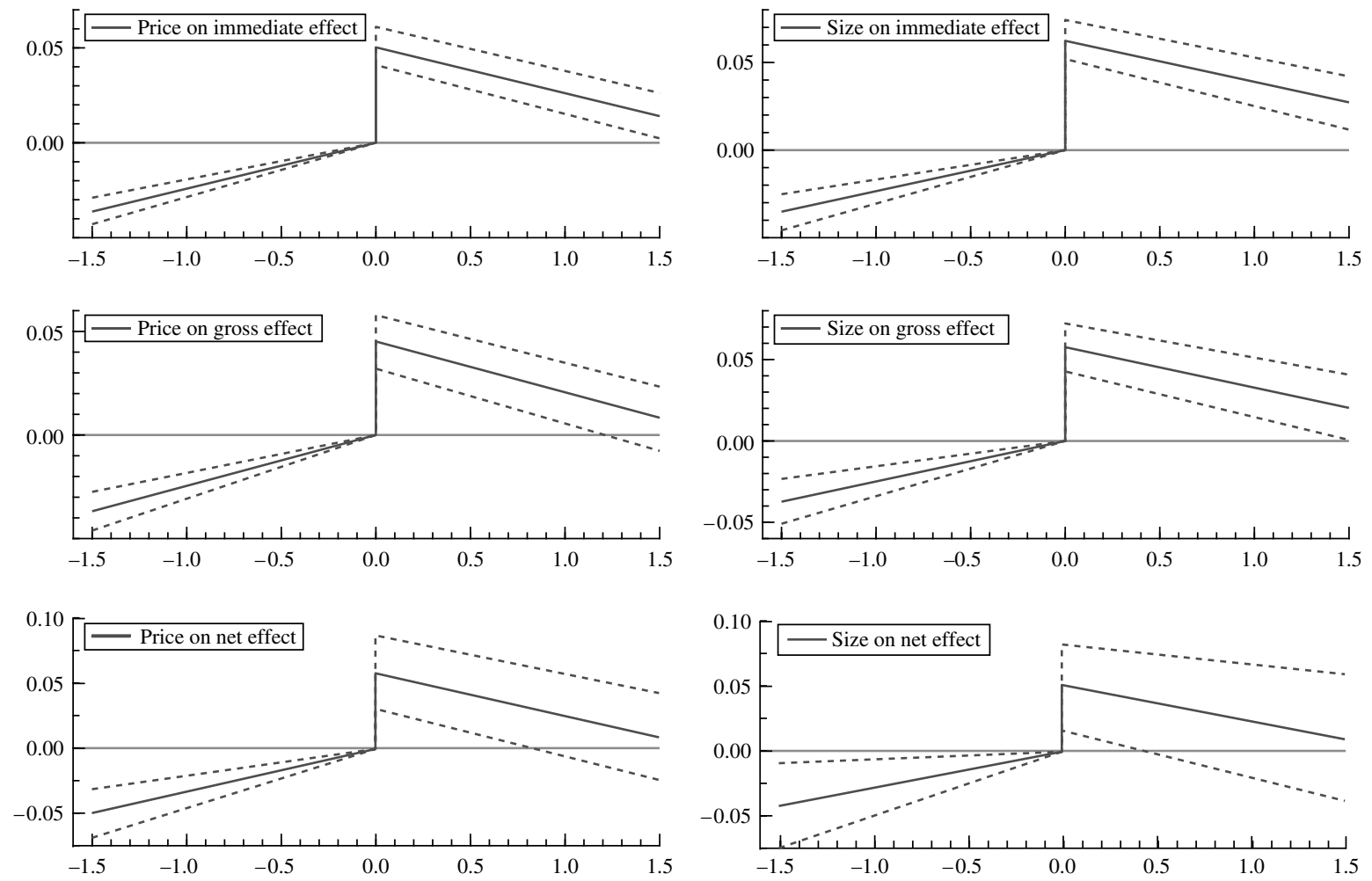

deviations. This confirms that the asymmetric price and share effects are stronger than the corresponding neighborhood effects.

The strong asymmetric effects, together with our results for the private label/national brand asymmetry, which is about twice the size of the asymmetric effects, confirm that the national brand/private label asymmetry has the greatest influence on crossbrand elasticity. First-level results confirm the importance of national brand/private label asymmetry. We constructed a table similar to Table 4 for only national brand (A)/private label (V) brand pairs (not reported), which reveals that of the 495 selected immediate cross-promotional effects, $99 \%$ are positive and $80 \%$ are significant at $95 \%$. Thus, positive and significant cross-promotional effects occur much more frequently for national brand (A)/private label (V) brand pairs than in general.

In addition to the asymmetric and neighborhood effects, we include brand- and category-specific variables in our model. We find notable results for these variables. Among the brand- and categoryspecific variables, brand-specific characteristics have a stronger influence. In addition, both the attacker and victim brands' promotional activities seem to have some influence on the cross-price effect, though those of the attacker play a much more important role overall (see Figure 3 and Table 5). Frequent use of price promotions by the victim brand increases, and

frequent and deep promotions by the attacker brand decrease the effect of the attacker's price promotions on the victim brand. As argued previously, these outcomes likely result from the eroded brand equity of a heavily promoted brand. In contrast, the frequent use of display and feature by the attacker increases the influence of its price promotions. Perhaps such a frequent use of display and feature increases consumers' awareness of the brand and therefore the likelihood of being in their consideration set. The average interpurchase time is the only category variable that significantly influences the cross-brand elasticity in the short run.

The victim's relative depth of price promotions and the frequency of feature and display are not relevant. This also holds for the category variables perishability, utilitarian, and budget share.

For competitive concentration, we find positive parameters, in line with our expectations. In more concentrated categories, customers have less opportunities to encounter price promotion opportunities. Thus, the price-sensitive segment may be more inclined to use these opportunities, which is reflected in the positive moderating parameter for the immediate effect. These customers may also have an especially strong inclination for preemptive switching, which is reflected in a positive and significant moderating parameter for the gross effect, approximately double the size of the corresponding parameter for 
the immediate effect. Finally, we find that categories with shorter interpurchase times face greater immediate, gross, and net cross-price promotional effects, in line with our expectations based on the literature.

What is the influence of consumer dynamics, and does a cross-brand post-promotional dip exist? Dynamic consumer responses do affect the cross-price promotional effect. Table 4 and Figure 2 both show that for the majority $(60 \%)$ of cross-brand pairs, the gross cumulative effect is larger than the immediate effect. This can also be observed by comparing the estimated intercept for the immediate and the gross effect in Table 5. Including consumer dynamics increases the cross-brand price elasticity between two similar, average national brands. This difference is statistically significant (zero not in 90\% HPD region) and provides evidence for a cross-brand post-promotion dip. The lack of more overwhelming evidence may be due to the differences in consumers' inclinations to stockpile across brands and categories.

Almost the same set of moderating variables is relevant in explaining the variation in cross-price elasticities when including consumer dynamics than for the immediate effect. The only exception is competitive concentration, which has a significant moderating effect on the gross elasticities but not on the immediate elasticities. However, we observe some changes in the impact of the moderating variables. The moderating impact of a variable on the crossbrand post-promotional dip is given by the impact of the variable on the gross effect less the impact on the immediate effect. If this difference is positive for a certain variable, an increase in the variable goes together with an increase in the cross-promotional dip. In general, these are positive for the frequency and depth of price promotions of the attacker brand, the average share and price levels, the two national brand-private label dummies, category budget share, and competitive concentration (see Table 5). So, we find, for example, that a national brand's price promotion not only induces substantial immediate switching from the private label brand but also results in preemptive switching, which further reduces sales of the victim private label brand in future periods. All changes together lead to an even more prominent national brand/private label asymmetry. We also observe that the results for the cross-brand postpromotion dip are in line with the findings on ownbrand post-promotion dips in, for example, Macé and Neslin (2004) and Fok et al. (2006). Thus, these variables influence stockpiling from both the promoted brand's and its competitors' customers, which leads to reduced sales of both the promoted brand and the competitor's in subsequent periods.

The other variables have no impact on the cross-brand post-promotional dip or have a negative impact. For example, the impact of the price asymmetry decreases when we account for consumer dynamic effects. Although a promotion of a highpriced brand induces consumers to switch away from lower-priced brands, they may not be able to afford stockpiling for future consumption. This behavior is likely related to the budget constraints of the consumer base of the low-priced brands.

What is the influence of competitive dynamics? Including competitive reactions further alters the influence of the moderating variables. A price promotion of brand A may induce brand $\mathrm{V}$ to react to mitigate its initial sales loss. If this response is successful, the net cross-price elasticity should be lower than the gross elasticity. However, competitive dynamics are more complex in reality, in that price promotions of brand A may stimulate brands other than $\mathrm{V}$ to respond, which would further reduce sales of brand V. Furthermore, competitive reactions by brand $\mathrm{V}$ or any other brand can cause a chain of competitive reactions.

Table 4 shows that for $59 \%$ of the cross-brand pairs, the net effect is larger than the gross effect. This is also reflected in the estimated intercepts; the intercept for the net effect is significantly larger (zero not in the $90 \%$ HPD region) than for the immediate effect. Figure 3 shows that the impact of most of the moderating variables is amplified when we also include competitive dynamics. Several variables remain significant for the net effect, even though competitive reactions induce substantial uncertainty in our results and thereby increase the standard deviations of the parameters of the second-level model considerably (column 4 of Table 5). Overall, the national brand $(\mathrm{A})$ /store brand $(\mathrm{V})$ asymmetry is still the most influential. The difference between the coefficient of this variable for the net effect versus the gross effect is significantly different from zero using the $80 \%$ HPD region.

Regarding the brand-specific variables, for the net effect, only the attacker's price promotion frequency remains significant, and competitive reactions amplify its influence. Thus, frequent price promotions seem especially harmful for the attacker brand. They not only erode brand equity, such that the brand attracts less brand switching and experiences lower immediate cross-brand elasticities, but also induce more competitive retaliation, as reflected by the lower moderating parameters for the net elasticities. The only category-specific variable that remains significant is competitive concentration. Competitive reactions also amplify the moderating effect of competitive concentration. Overall, competitive reactions accumulate rather than diminish cross-price elasticities and the effect of moderating variables.

\section{Conclusions and Discussion}

This study sheds new light on asymmetric and neighborhood cross-brand price effects, beyond prior 
research that has focused on immediate cross-brand promotional price estimates and considered the effects independently or, at best, with a limited set of alternative moderating factors. In particular, we offer evidence of price and share asymmetries, neighborhood price and share effects, and national brand/private label asymmetry in immediate crosspromotional elasticities, even when we include the effects jointly in a single model. These results also hold even when we integrate consumer and competitive dynamics. Thus, our results firmly reinforce the existence of these effects.

A new finding is the importance of a national brand/private label asymmetry. This asymmetry exists even after we control for price and share asymmetries. We find that this asymmetry has by far the strongest influence on cross-price elasticities, followed by the asymmetric price and share effects. Brandspecific characteristics, especially those of the attacker brand, also shape cross-price elasticities considerably.

An important result is that competitive reactions accumulate rather than diminish cross-price elasticities and the effect of moderating variables. These findings imply that competitive reactions result in losses for competitors. At first glance, this is a surprising result, because we would expect that victim brands would retaliate against the promotion of the attacker brand and thereby make up the sales losses suffered from the attacker's action. The literature provides several potential explanations for our finding. First, both Pauwels (2004) and Steenkamp et al. (2005) show that competitive reactions are as likely to be accommodating as retaliatory. Second, company inertia or retailer dynamic support may cause the initial promotion itself to last for more weeks (Pauwels 2004, 2007). Finally, this result may be due to the complex nature of competitive dynamics captured in our model. Price promotions of brand A probably hurt several competing brands on the market, not only brand V, whose sales suffered from the attacker's promotion. This may stimulate brands other than $\mathrm{V}$ to respond, which would further reduce sales of brand V. Furthermore, the price promotion of brand A can cause a chain of competitive reactions. The responsive move of brand $\mathrm{V}$ to the price promotion of brand A will hurt at least some of its competitors. As a result, these brands may react, and their price promotions may further reduce sales of $\mathrm{V}$ in the future.

Among the brand-specific variables, the attacker brand's promotional activities seem to most affect the cross-brand price promotional elasticities. This suggests that though a brand can effectively use a broad set of marketing tools to influence the effect of promotions on the sales of other brands, it is more limited in defending its own sales from other brands' promotions. Overall, the significant attacker characteristics coincide with the own brandspecific variables that influence own-brand elasticities. Apparently, some of these earlier established own effects arise from higher brand switching. For the net effect, among the brand-specific variables, only the attacker's price promotion frequency remains significant; competitive reactions amplify its influence.

Category characteristics have a limited influence on the cross-promotional price effect. Among these, competitive concentration and the average interpurchase time in the category have a moderate influence on the cross effects.

We also show that dynamic consumer responses and competitive reactions affect cross-brand price elasticities. Overall, the cross-promotional price effect tends to increase and the impact of moderating variables is amplified when dynamics are taken into account. This especially holds for the national brand/private label asymmetric effect. This provides evidence of the existence of preemptive switching, resulting in cross-brand post-promotional dips. Such stockpiling not only causes a dip for the promoted brand but also reduces sales of competing brands in future periods. We find that, on average, the cross-brand postpromotion dip is approximately $13 \%$ of the immediate cross effect and $25 \%$ of the own post-promotion dip. However, our results also suggest that the size of this dip varies, depending on consumers' inclination to stockpile for a brand and within a category.

\subsection{Implications}

Our results have implications for many open managerial and academic questions in the fast-moving consumer goods industry. We found a large private label/national brand asymmetry, such that private labels are vulnerable to national brands' promotions. Although private labels continue to improve their quality and market presence and aim to increase store loyalty (Sethuraman 2009), their customers can still be easily tempted by competing national brands' promotions. Therefore, to improve their performance and retail margins, private labels must first develop their customer loyalty. Some retailers have already begun advertising their private labels, which may be a suitable marketing tool to establish new associations in consumers' minds, reduce the quality gap perceptions, and increase brand equity and brand loyalty. Even if retailers cannot match the advertising intensity of national brands (Steenkamp et al. 2010), they could exploit their exceptionally high control over in-store marketing activities and the beneficial spillover effects from their store image (Ailawadi and Keller 2004) to build private label equity and loyalty. Improved brand associations related to perceived quality would also enable managers to increase private label prices without a significant loss in share. 
Thus, private labels should try to close the price gap with their national competitors.

Furthermore, we find that price and size asymmetry were more important in shaping cross-brand elasticities than the corresponding neighborhood effects. Thus, brands should monitor the higher-tier brands' promotional activities closely. This is important for logistic and profitability management of the brand.

Among the attacker and the victim brands' promotional activities, it is mainly the attacker brand that has some influence. This suggests that though a brand can effectively use a broad set of marketing tools to influence the effect of its promotions on the sales of other brands, it is more limited in defending its own sales from other brands' promotions.

Among the brand-specific variables, frequent price promotions are especially harmful for a brand. They result in lowered price and quality perceptions and increased price sensitivity of consumers (Mela et al. 1997) and, thus, erode brand equity. They also draw competitors' attention to the brand's activities. From the eroded brand equity, frequent promotions of a brand make the brand more vulnerable to other brands' price promotions, and its promotions attract less brand switching from others as well. Furthermore, frequent promotions induce more competitive retaliation, as reflected by the lower moderating parameters for the net elasticities. It takes considerable effort and money to build a strong brand and establish the appropriate associations. Frequent use of price promotions, driven by short-term goals, may, however, modify these associations and reduce brand performance in the long-run. Therefore, brand and category managers should consider this trade-off when determining promotional activities. The use of infrequent but deep discounts may be a better idea because they seem not to affect cross-price elasticities, indicating that they harm brand equity to a lesser extent.

Finally, our results on the effect of consumer responses and competitive reactions, and our findings for preemptive switching, suggest that cross-brand consumer and competitive dynamics exist. Thus, they must be taken into account when analyzing the effects of price deals on competitors' performance.

\subsection{Future Research}

This study could be extended in several ways. First, we restricted our analysis to the cross-price effects within a category. Additional analysis that includes possible moderating factors for cross-price effects across categories, such as complementarity and substitutability, would provide new insights into cross-price elasticities, which would be useful for both researchers and practitioners. Second, our results draw attention to the importance of private label brand loyalty. Many studies have investigated whether and how private labels boost store loyalty, but little research has examined whether and how developing private label loyalty might benefit retailers. An exception is Ailawadi et al. (2008), who show that private label share significantly affects three measures of behavioral loyalty that can benefit the retailer: share of wallet, share of items purchased, and share of shopping trips. Even if retailers cannot use advertising to the same extent as national brands to build and maintain brand equity, Keller (2008) suggests alternative ways to develop associations. Furthermore, retailers enjoy an advantage because of their high control over in-store marketing activities.

In addition, our analysis is based on a data set from the United States and contained a maximum of one private label brand in a category. Thus, further research could investigate whether our results prevail in a western European setting, in which average quality perceptions of private labels are higher and less uncertain, and the private label positioning is more consistent (Erdem et al. 2004). Moreover, in these markets, several private labels are often present in a category, allowing for private label tiers (especially premium private labels), and their presence influences perceptions of the incumbent private label and national brands (Geyskens et al. 2010).

Finally, our analysis pertains solely to fast-moving consumer goods. An important question would be whether our findings generalize to other categories, such as durable products or categories that induce greater involvement among customers.

\section{Acknowledgments}

The authors thank SymphonyIRI for making the data available. All estimates or analyses based on SymphonyIRI Group data are by the authors and not SymphonyIRI Group. Furthermore, the authors thank the editor, associate editor, and two anonymous reviewers for their valuable and constructive comments and suggestions. They are also grateful to Vera Blažević, Paul Driessen, Bas Hillebrand, and Richard Paap for their helpful comments on earlier versions of the paper.

\section{Appendix A. Bayesian Estimation}

In this appendix, we discuss the details of the Bayesian analysis of our model. We consider some technical details, including the conditional distributions used in the sampling algorithm. Furthermore, we present and motivate all priors used.

\section{A.1. Sales Models}

For the error correction model, we consider the exact likelihood function. For the first observation, lags are not available; therefore we set this observation equal to the long-run equilibrium level. That is,

$$
\log S_{c 1}=-\Pi_{1 c}^{-1} \mu_{c}+B_{c k} \log P_{c k 1}+\sum_{k=1}^{K} B_{c k}^{*} X_{c k 1}+\varepsilon_{c 1},
$$

with $\varepsilon_{1 c} \sim \mathrm{N}\left(0, V_{c}\right)$, where $V_{c}$ is the long-run variance. This variance can be obtained from solving the system by repeated substitution and is given by $V_{c}=\sum_{j=0}^{\infty}\left(\mathbf{I}+\Pi_{1 c}\right)^{j}$. 
$\Sigma_{c}\left(\mathbf{I}+\Pi_{1 c}^{\prime}\right)^{j}$. The variance is finite if the eigenvalues of $\left(\mathbf{I}+\Pi_{1 c}\right)$ are within the unit circle, that is, in case of stationarity.

To derive the likelihood function, we summarize the elements of $A_{c}$ and $B_{c}$, which are related to the immediate and gross own effects, respectively, in the $I_{c}$-dimensional vectors $\alpha_{c}=\left[A_{i i, c}\right]_{i=1}^{I_{c}}, \beta_{c}=\left[B_{i i, c}\right]_{i=1}^{I_{c}}$. For these parameters, we impose the hierarchical priors $\alpha_{i c} \sim \mathrm{N}\left(\mu_{\alpha}, \sigma_{\alpha}^{2}\right)$ and $\beta_{i c} \sim$ $\mathrm{N}\left(\mu_{\beta}, \sigma_{\beta}^{2}\right)$ for $i=1, \ldots, I_{c}, c=1, \ldots, C$. The second-stage equations (11) and (12) are compactly written as $\tilde{\alpha}_{l c}=$ $Z_{l c}^{\prime} \Theta_{1}+\eta_{l c}^{(1)}$ and $\tilde{\beta}_{l c}=Z_{l c}^{\prime} \Theta_{2}+\eta_{l c}^{(2)}$, where $Z_{l c}$ collects all variables in Equations (11) and (12). The likelihood function of the model for the sales in all categories is given by

$$
\begin{aligned}
& \prod_{c=1}^{C} \int_{\alpha_{c}, \beta_{c}} \int_{\tilde{\alpha}_{c}, \tilde{\beta}_{c}} \phi\left(\varepsilon_{c 1} ; 0, V_{c}\right) \prod_{t=2}^{T_{c}} \phi\left(\varepsilon_{c t} ; 0, \Sigma_{c}\right) \\
& \quad \cdot \prod_{i=1}^{I_{c}} \phi\left(\alpha_{i c} ; \mu_{\alpha}, \sigma_{\alpha}^{2}\right) \phi\left(\beta_{i c} ; \mu_{\beta}, \sigma_{\beta}^{2}\right) \\
& \quad \cdot \prod_{l=1}^{I_{c}\left(I_{c}-1\right)} \phi\left(\tilde{\alpha}_{l c} ; \Theta_{1}^{\prime} Z_{i c}, \sigma_{\eta^{(1)}}^{2}\right) \\
& \cdot \phi\left(\tilde{\beta}_{l c} ; \Theta_{2}^{\prime} Z_{l c}, \sigma_{\eta^{(2)}}^{2}\right) d \tilde{\alpha}_{c} d \tilde{\beta}_{c} d \alpha_{c} d \beta_{c},
\end{aligned}
$$

where $\phi(x ; \mu, \Sigma)$ is the density function of the (multivariate) normal distribution, with mean $\mu$ and variance $\Sigma$ evaluated at $x$.

To obtain posterior results for this part of the model, we use the Gibbs sampling technique of Geman and Geman (1984) with data augmentation; see Tanner and Wong (1987). The Bayesian analysis is largely based on uninformative priors for the model parameters. However, some priors are used. The settings for the prior parameters appear in $\S$ A.4.

Next, we derive the full conditional posterior distributions of the model parameters and all latent variables. In deriving the sampling distributions, we build on the general results of Zellner (1971, Chapter VIII) and Fok et al. (2006).

\section{Sampling of $\Pi_{1 c}$}

To sample $\Pi_{1 c}$, we rely on the Metropolis-Hastings sampler (Hastings 1970, Metropolis et al. 1953). As the candidate, we consider the distribution that would result if we ignore the first observation. We write Equation (1) as

$$
\begin{aligned}
& \Delta \log S_{c t}-\mu_{c}-A_{c} \log P_{c t}-\sum_{k=1}^{K} A_{c k}^{*} \Delta X_{c k t} \\
& \quad=\Pi_{1 c}\left(\log S_{c, t-1}-B_{c} \log P_{c, t-1}-\sum_{k=1}^{K} B_{c k}^{*} X_{c k, t-1}\right)+\varepsilon_{c t}
\end{aligned}
$$

and summarize this equation as $Y_{c t}=\Pi_{1 c} W_{c t}+\varepsilon_{c t}$, where $Y_{c t}$ and $W_{c t}$ denote the corresponding terms in Equation (17). Ignoring the observation for $t=1$, we would obtain a normal full conditional posterior distribution with mean $\hat{\Pi}_{1 c}^{\prime}$ and variance $\hat{\Sigma}_{\Pi_{1 c}^{\prime}}$ given by

$$
\begin{gathered}
\hat{\Pi}_{1 c}^{\prime}=\left(\sum_{t=2}^{T_{c}} W_{c t} W_{c t}^{\prime}\right)^{-1}\left(\sum_{t=2}^{T_{c}} W_{c t} Y_{c t}^{\prime}\right), \quad \text { and } \\
\hat{\Sigma}_{\Pi_{1 c}^{\prime}}=\left(\Sigma_{c} \otimes\left(\sum_{t=2}^{T_{c}} W_{c t} W_{c t}^{\prime}\right)^{-1}\right) .
\end{gathered}
$$

The sampled candidate is denoted by $\Pi_{1 c}^{\text {cand }}$. The difference in the candidate and the target density is only in the first observation, which gives as acceptance-rejection probability:

$$
\frac{\left.\phi\left(\varepsilon_{1 c} ; 0, V_{c}\right)\right|_{\Pi_{1 c}=\Pi_{1 c}^{\text {cand }}}}{\left.\phi\left(\varepsilon_{1 c} ; 0, V_{c}\right)\right|_{\Pi_{1 c}=\Pi_{1 c}^{\text {old }}}},
$$

where $\Pi_{1 c}^{\text {old }}$ denotes the previous draw and $\varepsilon_{c 1}=\log S_{c 1}+$ $\Pi_{1 c}^{-1} \mu_{c}-B_{c} \log P_{c 1}-\sum_{k=1}^{K} B_{c k}^{*} X_{c k 1}$. See Chib and Greenberg (1995) for a similar approach in an exact likelihood analysis of an autoregressive model. To ensure that all draws correspond to a stationary $\Pi_{1 c}$ matrix, we use a prior that assigns probability 0 if the largest eigenvalue of $\mathbf{I}+\Pi_{1 c}$ is larger than 0.95 . This is implemented by rejecting each $\Pi_{1 c}$ for which an eigenvalue exceeds 0.95 . This prior is further motivated in §A.4.

\section{Sampling of $\Sigma_{c}$}

For $\Sigma_{c}$, we also use a Metropolis-Hastings sampler in which we construct the candidate ignoring the first observations. The candidate $\Sigma_{c}^{\text {cand }}$ is sampled from an inverted Wishart distribution with scale parameter $\sum_{t=2}^{T_{c}} \varepsilon_{c t} \varepsilon_{c t}^{\prime}$ and $T_{c}-1$ degrees of freedom, where $\varepsilon_{c t}=$ $\Delta \log S_{c t}-\mu_{c}-A_{c} \log P_{c t}-\sum_{k=1}^{K} A_{c k}^{*} \Delta X_{c k t}-\Pi_{1 c}\left(\log S_{c, t-1}-\right.$ $\left.B_{c} \log P_{c, t-1}-\sum_{k=1}^{K} B_{c k}^{*} \Delta X_{c k, t-1}\right)$. The acceptance-rejection probability equals

$$
\frac{\left.\phi\left(\varepsilon_{1 c} ; 0, V_{c}\right)\right|_{\Sigma_{c}=\Sigma_{c}^{\text {cand }}}}{\left.\phi\left(\varepsilon_{1 c} ; 0, V_{c}\right)\right|_{\Sigma_{c}=\Sigma_{c}^{\text {old }}}},
$$

where $\Sigma_{c}^{\text {old }}$ denotes the previous draw of $\Sigma_{c}$.

Sampling of $\mu_{\alpha}, \mu_{\beta}$, and $\Theta_{n}, n=1,2$

The full conditional distributions of $\mu_{\alpha}$ and $\mu_{\beta}$ are $\mathrm{N}\left(\left(1 / \sum_{c=1}^{C} I_{c}\right) \sum_{c=1}^{C} \sum_{i=1}^{I_{c}} \alpha_{i c},\left(\sigma_{\alpha}^{2} / \sum_{c=1}^{C} I_{c}\right)\right)$ and $\mathrm{N}\left(\left(1 / \sum_{c=1}^{C} I_{c}\right)\right.$. $\left.\sum_{c=1}^{C} \sum_{i=1}^{I_{c}} \beta_{i c},\left(\sigma_{\beta}^{2} / \sum_{c=1}^{C} I_{c}\right)\right)$, respectively. The full conditional distribution of $\Theta_{1}$ is multivariate normal with mean $\left(\sum_{c=1}^{C} \sum_{l=1}^{I_{c}\left(I_{c}-1\right)} Z_{l c} Z_{l c}^{\prime}\right)^{-1}\left(\sum_{c=1}^{C} \sum_{l=1}^{I_{c}\left(I_{c}-1\right)} Z_{l c} \tilde{\alpha}_{l c}\right)$ and variance $\sigma_{\eta^{(1)}}^{2}\left(\sum_{c=1}^{C} \sum_{l=1}^{I_{c}\left(I_{c}-1\right)} Z_{l c} Z_{l c}^{\prime}\right)^{-1}$. The full conditional for $\Theta_{2}$ is analogous.

Sampling of $\sigma_{\alpha}^{2}, \sigma_{\beta^{2}}^{2}$ and $\sigma_{\eta^{(n)}}^{2}, n=1,2$

These variances are sampled from inverted chi-square distributions with scale parameter and degrees of freedom as defined in the following overview.

\begin{tabular}{lcc}
\hline Variance & Scale parameter & Degrees of freedom \\
\hline$\sigma_{\alpha}^{2}$ & $\kappa_{1}+\sum_{c=1}^{C} \sum_{i=1}^{I_{c}}\left(\alpha_{i c}-\mu_{\alpha}\right)^{2}$ & $\kappa_{2}+\sum_{c=1}^{C} I_{c}$ \\
$\sigma_{\beta}^{2}$ & $\kappa_{1}+\sum_{c=1}^{C} \sum_{i=1}^{I_{c}}\left(\beta_{i c}-\mu_{\beta}\right)^{2}$ & $\kappa_{2}+\sum_{c=1}^{C} I_{c}$ \\
$\sigma_{\eta^{(1)}}^{2}$ & $\kappa_{1}+\sum_{c=1}^{C} \sum_{l=1}^{I_{c}\left(I_{c}-1\right)}\left(\tilde{\alpha}_{l c}-Z_{l c}^{\prime} \Theta_{1}\right)^{2}$ & $\kappa_{2}+\sum_{c=1}^{C} I_{c}\left(I_{c}-1\right)$ \\
$\sigma_{\eta^{(2)}}^{2}$ & $\kappa_{1}+\sum_{c=1}^{C} \sum_{l=1}^{I_{c}\left(I_{c}-1\right)}\left(\tilde{\beta}_{l c}-Z_{l c}^{\prime} \Theta_{2}\right)^{2}$ & $\kappa_{2}+\sum_{c=1}^{C} I_{c}\left(I_{c}-1\right)$ \\
\hline
\end{tabular}

The $\kappa$ terms result from the priors, which we use to improve convergence of our Gibbs sampler (Hobert and Casella 1996). 


\section{Sampling of $\alpha_{c}$ and $\beta$}

We split up $P_{c t}=\left(P_{c 1 t}, \ldots, P_{c I_{c} t}\right)^{\prime}$ into the scalars $P_{c i t}^{\text {own }}=P_{c i t}$ and the row vectors $P_{c i t}^{\text {cross }}=\left[P_{c j t}\right]_{j=1 \neq i}^{I_{c}}$ to disentangle the own effects from the cross effects. Next, we define $P_{c t}^{\text {own }}=$ $\operatorname{diag}\left(P_{c 1 t}^{\text {own }}, \ldots, P_{c I_{c} t}^{\text {own }}\right)$ and $P_{c t}^{\text {cross }}=\operatorname{diag}\left(P_{c 1 t}^{\text {cross }}, \ldots, P_{c I_{c} t}^{\text {cross }}\right)$. To sample $\alpha_{c}$ and $\beta_{c}$ jointly, we write

$$
\begin{gathered}
\log S_{c 1}-\log P_{c 1}^{\mathrm{cross}} \tilde{\beta}_{c}-\sum_{k=1}^{K} B_{c k}^{*} X_{c k 1}+\Pi_{1 c}^{-1} \mu_{c} \\
=\left(0, \log P_{c 1}^{\mathrm{own}}\right)\left(\begin{array}{c}
\alpha_{c} \\
\beta_{c}
\end{array}\right)+\varepsilon_{c 1},
\end{gathered}
$$

and

$$
\begin{aligned}
\Delta & \log S_{c t}-\mu_{c}-\Pi_{1 c}\left(\log S_{c, t-1}-\log P_{c, t-1}^{\mathrm{cross}} \tilde{\beta}_{c}-\sum_{k=1}^{K} B_{c k}^{*} X_{c k, t-1}\right) \\
& -\Delta \log P_{c t}^{\mathrm{cross}} \tilde{\alpha}_{c}-\sum_{k=1}^{K} A_{c k}^{*} \Delta X_{c k t} \\
= & \left(\Delta \log P_{c t}^{\mathrm{own}},-\Pi_{1 c} \log P_{c, t-1}^{\mathrm{own}}\right)\left(\begin{array}{c}
\alpha_{c} \\
\beta_{c}
\end{array}\right)+\varepsilon_{c t}
\end{aligned}
$$

which we rewrite as $Y_{c t}=W_{c t}\left(\begin{array}{c}\alpha_{c} \\ \beta_{c}\end{array}\right)+\varepsilon_{c t}$, with the obvious definitions for $Y_{c t}$ and $W_{c t}$. The variance of $\varepsilon_{c 1}$ is $V_{c}$, and the variance of $\varepsilon_{c t}, t>1$ equals $\Sigma_{c}$. Note that we use different definitions for $W_{c t}$ and $Y_{c t}$ for $t=1$ versus $t>1$. Next, we write the hierarchical priors as $-\mu_{\alpha} \mathbf{I}=-\mathbf{I} \alpha_{c}+\nu_{c}^{1}$ and $-\mu_{\beta} \mathbf{I}=-\mathbf{I} \beta_{c}+\nu_{c}^{2}$. The error term $\nu_{c}^{n}$ is normal distributed with mean 0 and covariance matrix $\sigma_{\alpha}^{2} \mathbf{I}$ for $n=1$, and $\sigma_{\beta}^{2} \mathbf{I}$ for $n=2$. To sample $\alpha_{c}$ and $\beta_{c}$, we combine and standardize the equations

$$
\begin{gathered}
V_{c}{ }^{-1 / 2} Y_{c 1}=V_{c}{ }^{-1 / 2} W_{c 1}\left(\begin{array}{c}
\alpha_{c} \\
\beta_{c}
\end{array}\right)+V_{c}{ }^{-1 / 2} \varepsilon_{c 1}, \\
\Sigma_{c}{ }^{-1 / 2} Y_{c t}=\Sigma_{c}{ }^{-1 / 2} W_{c t}\left(\begin{array}{c}
\alpha_{c} \\
\beta_{c}
\end{array}\right)+\Sigma_{c}^{-1 / 2} \varepsilon_{c t}, \\
\left(\begin{array}{c}
-\frac{\mu_{\alpha}}{\sigma_{\alpha}} \mathbf{I} \\
-\frac{\mu_{\beta}}{\sigma_{\beta}} \mathbf{I}
\end{array}\right)=\left(\begin{array}{cc}
-\frac{1}{\sigma_{\alpha}} \mathbf{I} & 0 \\
0 & -\frac{1}{\sigma_{\alpha}} \mathbf{I}
\end{array}\right)\left(\begin{array}{l}
\alpha_{c} \\
\beta_{c}
\end{array}\right)+\left(\begin{array}{c}
\frac{1}{\sigma_{\alpha}} \nu_{c}^{1} \\
\frac{1}{\sigma_{\beta}} \nu_{c}^{2}
\end{array}\right),
\end{gathered}
$$

where $A^{-1 / 2}$ denotes the inverse of the Choleski decomposition of the matrix $A$; that is, $A^{-1 / 2}=\left(A^{1 / 2}\right)^{-1}$ with $A^{1 / 2} A^{1 / 2^{\prime}}=A$. Thus, the full conditional posterior distribution of $\left(\alpha_{c}^{\prime}, \beta_{c}^{\prime}\right)^{\prime}$ is normal with mean

$$
\begin{gathered}
\left(\left(\begin{array}{cc}
\frac{1}{\sigma_{\alpha}^{2}} \mathbf{I} & 0 \\
0 & \frac{1}{\sigma_{\beta}^{2}} \mathbf{I}
\end{array}\right)+W_{c 1}^{\prime} V_{c}^{-1} W_{c 1}+\sum_{t=2}^{T_{c}}\left(W_{c t}^{\prime} \Sigma_{c}^{-1} W_{c t}\right)\right)^{-1} \\
\cdot\left(\left(\begin{array}{l}
\frac{\mu_{\alpha}}{\sigma_{\alpha}^{2}} \mathbf{I} \\
\frac{\mu_{\beta}}{\sigma_{\beta}^{2}} \mathbf{I}
\end{array}\right)+\left(W_{c 1}^{\prime} V_{c}^{-1} Y_{c 1}\right)+\sum_{t=2}^{T_{c}}\left(W_{c t}^{\prime} \Sigma_{c}^{-1} Y_{c t}\right)\right.
\end{gathered}
$$

and covariance matrix

$$
\left(\left(\begin{array}{cc}
\frac{1}{\sigma_{\alpha}^{2}} \mathbf{I} & 0 \\
0 & \frac{1}{\sigma_{\beta}^{2}} \mathbf{I}
\end{array}\right)+W_{c 1}^{\prime} V_{c}^{-1} W_{c 1}+\sum_{t=2}^{T_{c}}\left(W_{c t}^{\prime} \Sigma_{c}^{-1} W_{c t}\right)\right)^{-1} .
$$

Sampling of $\mu_{c}, A_{c k}^{*}, B_{c k}^{*}, \tilde{\alpha}_{c}$, and $\tilde{\beta}_{c}$

Note that $\sum_{k=1}^{K} B_{c k}^{*} X_{c k, t-1}=\left(X_{c 1, t-1}^{\prime} \otimes \mathbf{I}, \ldots, X_{c K, t-1}^{\prime} \otimes \mathbf{I}\right)$. $\operatorname{vec}\left(B_{c 1}^{*}, \ldots, B_{c K}^{*}\right)$, which we define to equal $X_{c, t-1} \beta_{c}^{*}$. Furthermore, $\sum_{k=1}^{K} A_{c k}^{*} \Delta X_{c k t}$ equals $\left(\Delta X_{c 1 t}^{\prime} \otimes \mathbf{I}, \ldots, \Delta X_{c K t}^{\prime} \otimes \mathbf{I}\right)$. $\operatorname{vec}\left(A_{c 1}^{*}, \ldots, A_{c K}^{*}\right)$, which we denote by $\Delta X_{c, t} \alpha_{c}^{*}$. Equations (15) and (1) can now be written as

$\log S_{c 1}-\log P_{c 1}^{\text {own }} \beta_{c}$

$$
=\left(\begin{array}{lllll}
-\Pi_{1 c}^{-1} & 0 & \log P_{c 1}^{\text {cross }} & 0 & X_{c 1}
\end{array}\right) \gamma+\varepsilon_{c 1},
$$

$\Delta \log S_{c t}-\Delta \log P_{c t}^{\text {own }} \alpha_{c}-\Pi_{1 c}\left(\log S_{c, t-1}-\log P_{c, t-1}^{\text {own }} \beta_{c}\right)$

$=\left(\mathbf{I}_{I_{c}}, \Delta \log P_{c t}^{\text {cross }},-\Pi_{1 c} \log P_{c, t-1}^{\text {cross }}, \Delta X_{c t},-\Pi_{1 c} X_{c, t-1}\right) \gamma+\varepsilon_{c t}$,

where $\gamma=\left(\mu_{c}^{\prime}, \tilde{\alpha}_{c}^{\prime}, \tilde{\beta}_{c}^{\prime}, \alpha_{c}^{* \prime}, \beta_{c}^{* \prime}\right)$, and $\tilde{\alpha}_{c}$ and $\tilde{\beta}_{c}$ capture the cross effects in the matrices $A_{c}$ and $B_{c}$, respectively. This system can be written in the multivariate regression model $Y_{c t}=W_{c t} \gamma+\varepsilon_{c t}$, where $Y_{c t}$ contains the left-hand side of Equation (26) and $W_{c t}$ captures the right-hand side. Note that $W_{c 1}$ is differently defined from $W_{c t}$ for $t>1$. The error term is normal distributed with mean 0 and covariance matrix $\Sigma_{c}$ ( $V_{c}$ for the first observation).

In a similar manner as before, we write the information from the second layer of the hierarchical model as $-\tilde{U}_{c}^{1}=$ $-\mathbf{I}_{I_{c}\left(I_{c}-1\right)} \tilde{\alpha}_{c}+\eta_{c}^{(1)}$ and $-\tilde{U}_{c}^{2}=-\mathbf{I}_{I_{c}\left(I_{c}-1\right)} \tilde{\beta}_{c}+\eta_{c}^{(2)}$, where now $\tilde{U}_{c}^{n}$ equals an $I_{c}\left(I_{c}-1\right)$ vector with elements $Z_{l c}^{\prime} \Theta_{n}, n=1,2$. Collecting and standardizing both equations, we obtain

$$
\begin{aligned}
& V_{c}^{-1 / 2} Y_{c 1}=V_{c}^{-1 / 2} W_{c 1} \gamma+V_{c}^{-1 / 2} \varepsilon_{c 1}, \\
& \Sigma_{c}{ }^{-1 / 2} Y_{c t}=\Sigma_{c}{ }^{-1 / 2} W_{c t} \gamma+\Sigma_{c}^{-1 / 2} \varepsilon_{c t}, \\
& \left(\begin{array}{c}
-\frac{1}{\sigma_{\eta^{(1)}}} \tilde{U}_{c}^{1} \\
-\frac{1}{\sigma_{\eta^{(2)}}} \tilde{U}_{c}^{2}
\end{array}\right)=P \gamma+\left(\begin{array}{c}
\frac{1}{\sigma_{\eta^{(1)}}} \eta_{c}^{(1)} \\
\frac{1}{\sigma_{\eta^{(2)}}} \eta_{c}^{(2)}
\end{array}\right),
\end{aligned}
$$

where

$$
P=\left(\begin{array}{ccccc}
0 & -\frac{1}{\sigma_{\eta^{(1)}}} \mathbf{I}_{I_{c}\left(I_{c}-1\right)} & 0 & 0 & 0 \\
0 & 0 & -\frac{1}{\sigma_{\eta^{(2)}}} \mathbf{I}_{I_{c}\left(I_{c}-1\right)} & 0 & 0
\end{array}\right) .
$$

Thus, the full conditional distribution of $\gamma$ is normal with mean

$$
\begin{aligned}
& \left(P^{\prime} P+W_{c 1}^{\prime} V_{c}^{-1} W_{c 1}+\sum_{t=2}^{T_{c}}\left(W_{c t}^{\prime} \Sigma_{c}^{-1} W_{c t}\right)\right)^{-1} \\
& \left(\left(\begin{array}{c}
0 \\
\frac{1}{\sigma_{\eta^{(1)}}^{2}} \tilde{U}_{c}^{1} \\
\frac{1}{\sigma_{\eta^{(2)}}^{2}} \tilde{U}_{c}^{2}
\end{array}\right)+\left(W_{c 1}^{\prime} V_{c}^{-1} Y_{c 1}\right)+\sum_{t=2}^{T_{c}}\left(W_{c t}^{\prime} \Sigma_{c}^{-1} Y_{c t}\right)\right)
\end{aligned}
$$


and covariance matrix

$$
\left(P^{\prime} P+W_{c 1}^{\prime} V_{c}^{-1} W_{c 1}+\sum_{t=2}^{T_{c}}\left(W_{c t}^{\prime} \Sigma_{c}^{-1} W_{c t}\right)\right)^{-1} .
$$

\section{A.2. Price Model}

The model for the prices in category $c$ is a VARX. Note that we ignore the shrinkage effect from the hierarchical model for the net effects. For each category, we can therefore separately perform a Bayesian analysis. We rewrite the original model

$$
\begin{aligned}
\Delta \log P_{c t}= & \delta_{c}+D_{c} \log S_{c, t-1}+\Pi_{2 c} \log P_{c, t-1} \\
& +\sum_{k=1}^{K} D_{c k}^{*} X_{k, c t}+\xi_{c t}
\end{aligned}
$$

as $\Delta \log P_{c t}=M_{c t} \phi_{c}+\xi_{c t}$, where $M_{c t}=\left(\mathbf{I}, \mathbf{I} \otimes \log S_{c, t-1}^{\prime}, \mathbf{I} \otimes\right.$ $\left.\log P_{c, t-1}^{\prime}, \mathbf{I} \otimes X_{1, c t}, \ldots, \mathbf{I} \otimes X_{K, c t}\right)$ and where $\phi=$ $\left(\delta_{c}^{\prime}, \operatorname{vec}\left(D_{c}\right)^{\prime}, \operatorname{vec}\left(\Pi_{2 c}\right)^{\prime}, \operatorname{vec}\left(D_{c 1}^{*}\right)^{\prime}, \ldots, \operatorname{vec}\left(D_{c 1}^{*}\right)^{\prime}\right)^{\prime}$. We allow for a normal prior distribution on $\phi$ with mean $\bar{\phi}$ and inverse variance $\Sigma_{\phi}^{-1}$. Furthermore, $\xi_{c t} \sim \mathrm{N}\left(0, \Omega_{c}\right)$. Conditional on $\Omega_{c}$ and the data, $\phi_{c}$ has a normal distribution with mean

$$
\left(\sum_{t=2}^{T_{c}} M_{c t}^{\prime} \Omega^{-1} M_{c t}+\Sigma_{\phi}^{-1}\right)^{-1}\left(\sum_{t=2}^{T_{c}} M_{c t}^{\prime} \Omega_{c}^{-1} \Delta \log P_{c t}+\Sigma_{\phi}^{-1} \mu_{\phi}\right) .
$$

Conditional on $\phi_{c}$ and the data, $\Omega$ has an inverted Wishart distribution with scale matrix $\sum_{t=2}^{T_{c}}\left(\Delta \log P_{c t}-M_{c t} \gamma_{c}\right)$. $\left(\Delta \log P_{c t}-M_{c t} \gamma\right)^{\prime}$, and $T_{c}-1$ degrees of freedom.

\section{A.3. Net Effects}

We obtain draws of the net effect. For each such draw, we take one draw from the joint posterior of all sales models and one draw from the joint posterior of the price models. Next, we use Equation (9) to obtain a draw for the net effects. We denote such a draw by $\gamma_{c}^{(h)}$ for $c=1, \ldots, C$. We then use these draws to obtain pseudo-posterior draws of $\Theta_{3}$ in $\tilde{\gamma}_{l c}=Z_{l c}^{\prime} \Theta_{3}+\eta_{l c}^{(3)}$.

Overall, the MCMC chain to sample $\Theta_{3}$ and $\sigma_{\eta^{(3)}}^{2}$ is straightforward. The $h$ th draw for $\Theta_{3}$ comes from a normal with mean $\left(\sum_{l} Z_{l c} Z_{l c}^{\prime}\right)^{-1} \sum_{l} Z_{l c} \gamma_{l c}^{(h)}$ and variance $\sigma_{\eta^{(3)}}^{{ }^{(h-1)}}\left(\sum_{l} Z_{l c} Z_{l c}^{\prime}\right)^{-1}$. The $h$ th draw of $\sigma_{\eta^{(3)}}^{2}$ comes from an inverted chi-square with location $\kappa_{1}+\sum_{l}\left(\gamma_{l c}^{(h)}-Z_{l c}^{\prime} \Theta_{3}\right)^{2}$ and degrees of freedom equal to $\kappa_{2}+\sum_{c=1}^{C} I_{c}\left(I_{c}-1\right)$.

\section{A.4. Prior Settings}

For the gross cumulative effect to exist, we theoretically must ensure that zero posterior mass for values of $\Pi_{1 c}$ corresponds to nonstationary sales. Therefore, we impose a prior that restricts $\Pi_{1 c}$ to the stationary region. This prior is implemented by rejecting a draw if the largest eigenvalue of $\mathbf{I}+\Pi_{1 c}$ is larger than 0.95 . Note that this also rules out extremely large gross cumulative effects. Note that such a prior is only justified if the sales are actually stationary. We checked this assumption by counting the number of rejected draws. We only needed to reject 779 draws of the total $165 \times 10,000$ draws. This is less than $0.005 \%$. Thus, the assumption of stationarity is empirically justified.

Next, to improve convergence of the MCMC sampler, we impose some weak prior information on the variances in the second-level models. We use an inverted chi-square prior with scale $\kappa_{1}=1$ and degrees of freedom equal to $\kappa_{2}=5$ (see Hobert and Casella 1996 for a discussion).

For the net effects to exist, the combined model for price and sales as given in Equation (5) must be stationary. Note that it is not strictly necessary that the VARX model for prices in Equation (2) be stationary because the sales also depend on prices. To avoid very extreme and theoretically unlikely draws for the net effect, we set normal priors on the elements of $\Pi_{2 c}$. We set the corresponding elements of $\bar{\phi}$ and $\Sigma_{\psi}^{-1}$ to -0.8 and 25 for the own effects and to 0 and 25 for the cross effects, respectively. These settings roughly correspond to a prior confidence interval for the autoregressive parameters on the diagonal of $\mathbf{I}+\Pi_{2 c}$ of $[-0.2,0.6]$; for the off-diagonal elements, the interval is $[-0.4,0.4]$. To assess the impact of this prior, we reran the analysis after doubling the intervals to $[-0.6,1]$ and $[-0.8,0.8]$, respectively. Doing so only led to small changes in the posterior means of the impact of the moderating variables on the net effect. The presence of some extreme draws of the net effect for individual brands did increase the posterior standard deviation. The other parameters in the price models have a flat prior or an uninformative one.

\section{Appendix B. Controlling for Product Introductions/Deletions}

Changes in the number of products available in a category can have a major impact on a market. In our model, we control for this by including the number of products available for each brand as additional explanatory variables. This information is not directly available in the data. In this appendix, we discuss how we construct these variables.

First, we use the raw data to count the number of unique products (defined using the universal product code, or UPC) sold for each brand in each week; we denote this variable for brand $i$ in week $t$ as $\# \mathrm{UPC}_{i t}$. However, $\# \mathrm{UPC}_{i t}$ shows a lot of variation that is not related to product introductions or deletions but actually caused by the total brand sales. For example, when sales are relatively low in a particular week, some of the less popular UPCs will not be sold at all. Therefore, just including $\#^{U P C} C_{i t}$ in a sales model would lead to an endogeneity problem. We solve this problem by removing all short-term variation from \#UPC ${ }_{i t}$ that is not related to changes in the assortment. We do so by applying the following rules to all brands and all weeks; that is, we first apply rule 1 to all weeks, then rule 2, and so forth.

Rule 1: Remove temporary dips of length 1. If $\mathrm{HUPC}_{i t}<$ $\min \left\{\# \mathrm{UPC}_{i, t-1}, \mathrm{HUPC}_{i t+1}\right\}$, the low observed assortment size is most likely not due to a deletion. We replace $\mathrm{HPC}_{i t}$ by $\min \left\{\# \mathrm{UPC}_{i, t-1}, \mathrm{\# UPC}_{i t+1}\right\}$.

Rule 2: Remove temporary dips of length 2. If $\# \mathrm{UPC}_{i t}<$ $\min \left\{\# \mathrm{UPC}_{i, t-1}, \# \mathrm{UPC}_{i t+2}\right\}$ and $\# \mathrm{UPC}_{i t+1}<\min \left\{\# \mathrm{UPC}_{i, t-1}\right.$, $\left.\# \mathrm{UPC}_{i t+2}\right\}$, the low observed assortment size at $t$ and $t+$ 1 is most likely not due to a deletion. We set $\# \mathrm{UPC}_{i t}=$

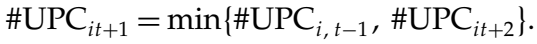

Rule 3: Remove temporary dips of length 3. If $\mathrm{HUPC}_{i t}<$ $\min \left\{\# \mathrm{UPC}_{i, t-1}, \#_{\mathrm{UPC}} \mathrm{C}_{i t+3}\right\}$ and $\# \mathrm{UPC}_{i t+1}<\min \left\{\# \mathrm{UPC}_{i, t-1}\right.$, $\left.\# \mathrm{UPC}_{i t+3}\right\}$, and $\# \mathrm{UPC}_{i t+2}<\min \left\{\# \mathrm{UPC}_{i, t-1}, \# \mathrm{UPC}_{i t+3}\right\}$, we set $\# \mathrm{UPC}_{i t}=\#_{\mathrm{UPC}}{ }_{i t+1}=\# \mathrm{UPC}_{i t+2}=\min \left\{\# \mathrm{UPC}_{i, t-1}\right.$, \#UPC $\left._{i t+3}\right\}$. 
Rule 4: Remove temporary peaks of length 1. If $\#_{\mathrm{UPC}_{i t}}>$ $\max \left\{\# \mathrm{UPC}_{i, t-1} \# \mathrm{UPC}_{i, t+1}\right\}$, the high assortment size at time $t$ is most likely not due to a real product introduction. Therefore, we replace this value with $\max \left\{\# \mathrm{UPC}_{i, t-1} \# \mathrm{UPC}_{i, t+1}\right\}$.

After applying these rules, we obtain series that reflect the true development in the assortment. All the spurious short-term variation is removed. Plots of the resulting \#UPC series are available from the authors upon request.

\section{References}

Agarwal MK (2002) Asymmetric price effects in the telecommunication services markets. J. Bus. Res. 55:671-677.

Aggarwal P, Cha T (1998) Asymmetric price competition and store vs. national brand choice. J. Product Brand Management 7:244-253.

Ailawadi KL, Keller KL (2004) Understanding retail branding: Conceptual insights and research priorities. J. Retailing 80:331-342.

Ailawadi KL, Neslin SA, Gedenk K (2001) Pursuing the valueconscious consumer: Store brands versus national brand promotions. J. Marketing 65:71-89.

Ailawadi KL, Pauwels K, Steenkamp J-BEM (2008) Private-label use and store loyalty. J. Marketing 72:1-22.

Ailawadi KL, Gedenk K, Lutzky C, Neslin SA (2007) Decomposition of the sales impact of promotion-induced stockpiling. J. Marketing Res. 44:450-467.

Allenby GM, Rossi PE (1991) Quality perceptions and asymmetric switching between brands. Marketing Sci. 10:185-204.

Allenby GM, Garratt MJ, Rossi PE (2010) A model for trade-up and change in considered brands. Marketing Sci. 29:40-56.

Balachander S, Ghosh B, Stock A (2010) Why bundle discounts can be a profitable alternative to competing on price promotions. Marketing Sci. 29:624-638.

Bartha R, Sinha I (2000) Consumer-level factors moderating the success of private label brands. J. Retailing 76:125-191.

Bawa K, Shoemaker RW (1987) The effects of a direct mail coupon on brand choice behavior. J. Marketing Res. 24:370-376.

Bell DR, Chiang J, Padmanabhan V (1999) The decomposition of promotional response: An empirical generalization. Marketing Sci. 18:504-526.

Bijmolt THA, Van Heerde HJ, Pieters RGM (2005) New empirical generalizations on the determinants of price elasticity. J. Marketing Res. 42:141-156.

Blattberg RC, Neslin SA (1989) Sales promotion: The long and the short of it. Marketing Lett. 1:81-97.

Blattberg RC, Wisniewski KJ (1989) Price-induced patterns of competition. Marketing Sci. 8:291-309.

Blattberg RC, Eppen GD, Lieberman J (1981) A theoretical and empirical evaluation of price deals for consumer nondurables. J. Marketing 45:116-129.

Bronnenberg BJ, Wathieu L (1996) Asymmetric promotion effects and brand positioning. Marketing Sci. 15:379-394.

Bronnenberg BJ, Kruger MW, Mela CF (2008) The IRI marketing data set. Marketing Sci. 27:745-748.

Bronnenberg BJ, Mahajan V, Vanhonacker VR (2000) The emergence of market structure in new repeat-purchase categories: The interplay of market share and retailer distribution. J. Marketing Res. 37:16-31.

Bucklin RE, Gupta S (1999) Commercial use of UPC scanner data: Industry and academic perspectives. Marketing Sci. 18:247-273.

Chib S, Greenberg E (1995) Understanding the Metropolis-Hastings algorithm. Amer. Statistician 49:327-335.

Chintagunta P (1993) Investigating purchase incidence, brand choice and purchase quantity decisions of households. Marketing Sci. 12:184-208.

DeChernatony LKD, Johnson G (1993) A cognitive perspective on managers' perceptions of competition. J. Marketing Management 9:373-381.
Dekimpe MG, Hanssens DM, Silva-Risso JM (1999) Long-run effects of price promotions in scanner markets. J. Econometrics 89:269-291.

Dhar SK, Hoch SJ (1997) Why store brand penetration varies by retailer. Marketing Sci. 16:208-227.

Dolan RJ, Jeuland AP (1981) Experience curves and dynamic demand models: Implications for optimal pricing strategies. J. Marketing 45:52-62.

Dutton JE, Jackson SE (1987) Categorizing strategic issues: Links to organizational action. Acad. Management Rev. 12:76-90.

Ehrenberg ASC, Goodhardt GJ, Barwise TP (1990) Double jeopardy revised. J. Marketing 54:82-91.

Erdem T, Zhao Y, Valenzuela A (2004) Performance of store brands: A cross-country analysis of consumer store-brand preferences, perceptions, and risk. J. Marketing Res. 41:86-100.

Fok D, Horváth C, Paap R, Franses PH (2006) A hierarchical Bayes error correction model to explain dynamic effects of price changes. J. Marketing Res. 43:443-461.

Fornell C (1992) A national customer satisfaction barometer: The Swedish experience. J. Marketing 56:6-21.

Fox J (2008) Applied Regression Analysis and Generalized Linear Models (Sage Publications, New York).

Garretson JA, Fisher D, Burton S (2002) Antecedents of private label attitude and national brand promotion attitude: Similarities and differences. J. Retailing 78:91-99.

Gatignon H, Robertson TS, Fein AJ (1997) Incumbent defense strategies against new product entry. Internat. J. Res. Marketing 14:163-176.

Geman S, Geman D (1984) Stochastic relaxations, Gibbs distributions, and the Bayesian restoration of images. IEEE Trans. Pattern Anal. Machine Intelligence 6:721-741.

Geweke JF (1992) Evaluating the accuracy of sampling-based approaches to the calculation of posterior moments. Bayesian Statistics, Vol. 4 (Oxford University Press, Oxford, UK), 169-193.

Geyskens I, Gielens K, Gijsbrechts E (2010) Proliferating privatelabel portfolios: How introducing economy and premium private labels influences brand choice. J. Marketing Res. 47:791-807.

Hansen K, Singh V, Chintagunta P (2006) Understanding storebrand purchase behavior across categories. Marketing Sci. 25:75-90.

Hardie B, Johnson E, Fader P (1993) Modeling loss aversion and reference dependence effects on brand choice. Marketing Sci. 12:378-394.

Hastings WK (1970) Monte Carlo sampling methods using Markov chains and their applications. Biometrika 57:97-109.

Hauser JR, Wernerfelt B (1989) The competitive implications of relevant-set/response analysis. J. Marketing Res. 26:391-405.

Hobert JP, Casella G (1996) The effect of improper priors on Gibbs sampling in hierarchical linear mixed models. J. Amer. Statist. Assoc. 91:1461-1473.

Horváth C, Leeflang PSH, Wieringa JE, Wittink DR (2005) Competitive reaction and feedback effects based on VARX models of pooled store data. Internat. J. Res. Marketing 22:415-426.

Jedidi K, Mela CF, Gupta S (1999) Managing advertising and promotion for long-run profitability. Marketing Sci. 18:1-22.

Kamakura W, Russell G (1989) A probabilistic choice model for market segmentation and elasticity structure. J. Marketing Res. 26:379-390.

Keller KL (1993) Conceptualizing, measuring, and managing customer-based brand equity. J. Marketing 57:1-22.

Keller KL (2008) Strategic Brand Management, 3rd ed. (Prentice-Hall, Upper Saddle River, NJ).

Kopalle PK, Mela CF, Marsh L (1999) Dynamic effect of discounting on sales: Empirical analysis and normative pricing implications. Marketing Sci. 18:317-332.

Lal R (1990) Price promotions: Limiting competitive enchroachment. Marketing Sci. 9:247-262. 
Leeflang PSH, Wittink DR (1992) Diagnosing competitive reactions using (aggregated) scanner data. Internat. J. Res. Marketing 9:39-57.

Leeflang PSH, Wittink DR (1996) Competitive reaction versus consumer response: Do managers overreact? Internat. J. Res. Marketing 13:103-119.

Leeflang PSH, Wittink DR (2001) Explaining competitive reaction effects. Internat. J. Res. Marketing 18:119-137.

Macé S, Neslin SA (2004) The determinants of pre- and postpromotion dips in sales of frequently purchased goods. J. Marketing Res. 41:339-350.

Martin CR (1973) The theory of double jeopardy. J. Acad. Marketing Sci. 1:148-155.

Mela CF, Gupta S, Jedidi K (1998) Assessing long-term promotional influences on market structure. Internat. J. Res. Marketing 15:89-107.

Mela CF, Gupta S, Lehmann DR (1997) The long-term impact of promotion and advertising on consumer brand choice. J. Marketing Res. 34:248-261.

Metropolis N, Rosenbluth AW, Rosenbluth MN, Teller AH, Teller E (1953) Equation of state calculations by fast computing machines. J. Chem. Phys. 21(6):1087-1092.

Narasimhan C, Neslin SA, Sen SK (1996) Promotional elasticities and category characteristics. J. Marketing 60:17-30.

Nijs VR, Dekimpe MG, Steenkamp J-BEM, Hanssens DM (2001) The category-demand effects of price promotions. Marketing Sci. 20:1-22.

Pauwels K (2004) How dynamic consumer response, competitor response, company support, and company inertia shape longterm marketing effectivenes. Marketing Sci. 23:596-610.

Pauwels K (2007) How retailer and competitor decisions drive the long-term effectiveness of manufacturer promotions for fast moving consumer goods. J. Retailing 83:297-308.

Pauwels K, Hanssens DM, Siddarth S (2002) The long-term effect of price promotions on category incidence, brand choice, and purchase quality. J. Marketing Res. 39:421-439.

Raj SP (1985) Striking a balance between brand popularity and brand loyalty. J. Marketing 49:53-59.

Raju JS (1992) The effect of price promotions on variability in product category sales. Marketing Sci. 11:207-220.

Raju JS, Sethuraman R, Dhar SK (1995) The introduction and performance of store brands. Management Sci. 41:957-978.

Ramaswamy V, Gatignon H, Reibstein DJ (1994) Competitive marketing behavior in industrial markets. J. Marketing 58:45-55.

Rao RC (1991) Pricing and promotions in asymmetric duopolies. Marketing Sci. 10:131-144

Rao AG, Miller PB (1975) Advertising/sales response functions. J. Advertising Res. 15:7-15.

Rao RC, Arjunji RV, Murthi BPS (1995) Game theory and empirical generalizations concerning competitive promotions. Marketing Sci. 14(Supplement):G89-G100.

Reibstein DJ, Farris PW (1995) Market share and distribution: A generalization, a speculation, and some implications. Marketing Sci. 14(Supplement):G190-G202.

Rothe JT, Lamont LM (1973) Purchase behavior and brand choice determinants. J. Retailing 49:19-33.

Russel G (1992) A model of latent symmetry in cross-price elasticities. Marketing Lett. 3:157-169.

Sayman S, Hoch SJ, Raju JS (2002) Positioning of store brands. Marketing Sci. 21:378-397.
Sethuraman R (1995) A meta-analysis of national brand and store brand cross-promotional price elasticities. Marketing Lett. 6:275-286.

Sethuraman R (2009) Assessing the external validity of analytical results from national brand and store brand competition models. Marketing Sci. 28:759-781.

Sethuraman R, Srinivasan V (2002) The asymmetric share effect: An empirical generalization on cross-price effects. J. Marketing Res. 61:71-84.

Sethuraman R, Srinivasan V, Kim D (1999) Asymmetric and neighborhood cross-price effects: Some empirical generalizations. Marketing Sci. 18:23-41.

Sivakumar K (2000) Price-tier competition: An integrative review. J. Product Brand Management 9:276-297.

Sivakumar K (2003) Price-tier competition: Distinguishing between intertier competition and intratier competition. J. Bus. Res. 56:947-959.

Sivakumar K (2004) Manifestations and measurement of asymmetric brand competition. J. Bus. Res. 57:813-820.

Sivakumar K (2007) Asymmetric quality-tier competition: An alternative explanation. J. Product Brand Management 16:416-421.

Sivakumar K, Raj SP (1997) Quality tier competition: How price change influences brand choice and category choice. J. Marketing 39:379-386.

Srinivasan S, Leszczyc PTLP, Bass FM (2000) Market share response and competitive interaction: The impact of temporary, evolving and structural changes in prices. Internat. J. Res. Marketing 17:281-305.

Steenkamp J-BEM, van Heerde H, Geykens I (2010) What makes consumers willing to pay a price premium for national brands over private labels? J. Marketing Res. 47:1011-1024.

Steenkamp J-BEM, Nijs VR, Hanssens DM, Dekimpe MG (2005) Competitive reactions to advertising and promotion attacks. Marketing Sci. 24:35-54

Tanner MA, Wong WH (1987) The calculation of posterior distributions by data augmentation. J. Amer. Statist. Assoc. 82:528-550.

Van Heerde HJ, Gupta S, Wittink DR (2003) Is 75\% of the sales promotion dump due to brand switching? no, only $33 \%$ is. J. Marketing Res. 40:481-491.

Van Heerde HJ, Helsen K, Dekimpe MG (2007) The impact of a product-harm crisis on marketing effectiveness. Marketing Sci. 26:230-245.

Van Heerde HJ, Srinivasan S, Dekimpe MG (2010) Estimating cannibalization rates for pioneering innovations. Marketing Sci. 29:1024-1039.

Wakefield KL, Inman JJ (2003) Situational price sensitivity: The role of consumption occasion, social context and income. J. Retailing 79:199-212.

Wedel M, Zhang J (2004) Analyzing brand competition across subcategories. J. Marketing Res. 41:448-456.

Yoo B, Donthu N, Lee S (2000) An examination of selected marketing mix elements and brand equity. J. Acad. Marketing Sci. 28:195-211.

Zellner A (1971) An Introduction to Bayesian Inference in Econometrics (John Wiley \& Sons, New York).

Zenor MJ, Bronnenberg BJ, McAlister L (1998) The impact of marketing policy on promotional price elasticities and baseline sales. J. Retailing Consumer Services 5:25-32. 